\title{
Gas Release from Irradiated Solids
}

April 1976

Prepared for the Energy Research and Development Administration under Contract E(45-1): 1830

\section{Battelle}


NOTICE

This report was prepared as an account of work sponsored by the United States Government. Neither the United States nor the United States Energy Research and Development Administration, nor any of their employees, nor any of their contractors, subcontractors. or their employees, makes any warranty, express or implied. or assumes any legal liability or responsibility for the accuracy, completeness or usefulness of any information, apparatus, product or process disclosed, or represents that its use would not infringe privately owned rights.

PACIFIC NORTHWEST LABORATORY operated by

BATTELLE

for the

U.S. ENERGY RESEARCH AND DEVELOPMENT ADMINISTRATION

Under Contract $E(45-1)-1830$

\author{
Printed in the United States of America \\ Available from \\ National Technical Information Service \\ U.S. Department of Commerce \\ 5285 Port Royal Road \\ Springfield, Virginia 22151
}

Price: Printed Copy \$5.50; Microfiche $\$ 2.25$ 


\section{6}

BNWL-2002

GAS RELEASE FROM IRRADIATED SOLIDS

by

L. C. $01 \operatorname{sen}^{\star}$

Joint Center For Graduate Study

Richland, Washington

Apri1 1976

Battelle

Pacific Northwest Laboratories

Richland, Washington 99352

*Consultant to the Ceramics and Graphite Section, Materials Department, Pacific Northwest Laboratories. 


\section{CONTENTS}

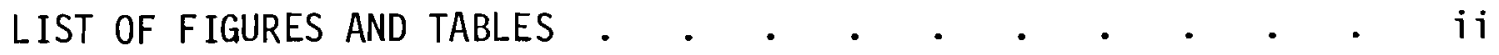

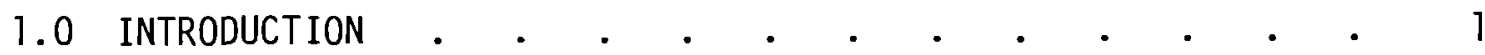

2.0 EXPERIMENTAL APPROACH

3.0 OVERVIEW OF PREV IOUS INERT GAS RELEASE STUDIES • • • • • 6

3.1 ELLEMAN'S STUDIES . • • • • • • . • • • . 6

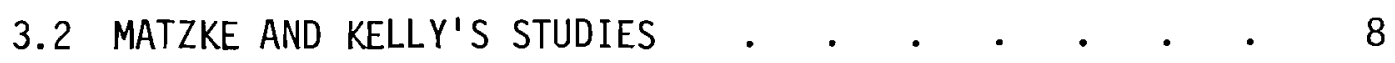

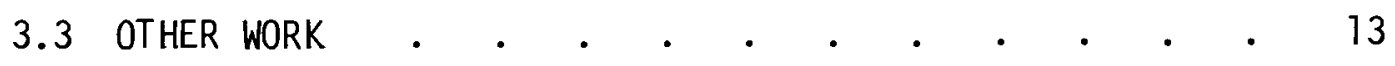

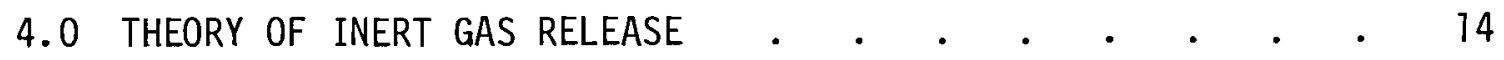

4.1 GENERAL APPROACH TO DIFFUSION PROBLEM . . . • . 14

4.2 PROBLEMS FOR A HOMOGENEOUS SOLID . • • • • • • • 16

4.2.1 Semi-Infinite Solid wi thout Trapping . . . 16

4.2.2 Semi-Infinite Solid with Surface

Transfer Coefficient . . . . . . 18

4.2.3 Slab with Reversible Trapping . . . . . 20

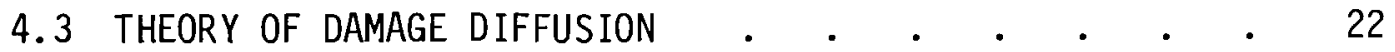

4.4 GAS RELEASE FROM A COMPOSITE SOLID . • • • • • • 25

4.4.1 Composite Semi-Infinite Solid without

Trapping by Green's Function . • . • • 27

4.4.2 Two Region Slab without Trapping by Eigenfunction Expansion. . • . . . . 29

4.4.3 Composite Solid with Reversible Trapping . • 31

4.5 COMPUTER CODE FOR GAS RELEASE CALCULATIONS • • • 33

5.0 INITIAL CONCENTRATION PROFILE • • • • • • • • • • • • 37

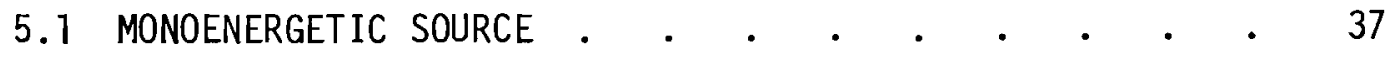

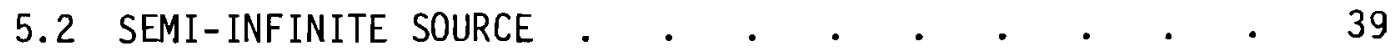

5.3 CONCENTRATION PROFILE FOR ARBITRARY N(E) • • • • • 42

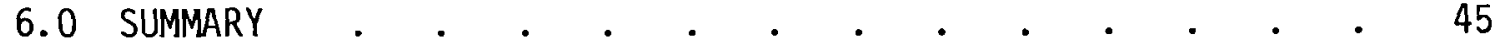

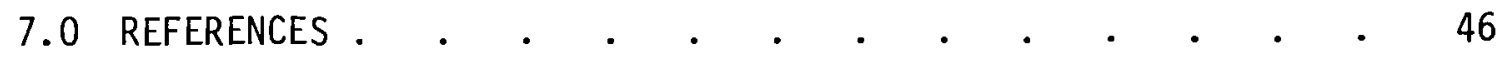

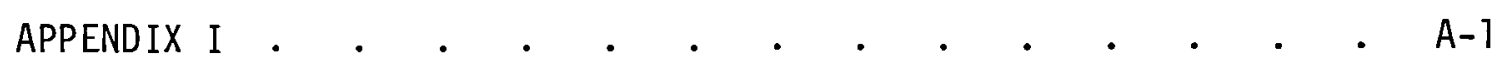

APPENDIX II $• . \quad \cdot \quad \cdot \quad \cdot \quad \cdot \quad \cdot \quad \cdot \quad \cdot \quad \cdot \quad \cdot \quad \cdot A-3$ 


\section{LIST OF FIGURES}

1 Typical Approach to Presenting Gas Release Data for

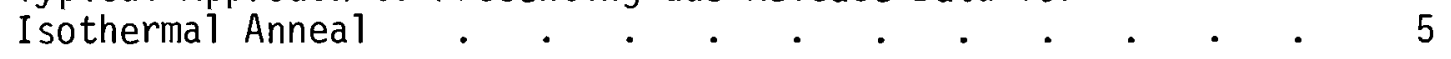

2 Typical Approach to Presenting Gas Release Data for Case
of Temperature Increasing Linearly with Time. . . . . 5

3 Problem Geometry for Solid of Thickness w . • • • . 17

4 Partitioned Semi-Infinite Solid Utilized in Kelly's Model for Calculating Gas Release during Annealing of Bombardment Disorder . . . . . . . . . . 24

5 Geometry for Two-Region Composite Diffusion Problem . . . 27

6 Release Fraction for Two-Region Composite Sol id without Trapping versus Dimensionless Time . . . . . 34

7 Release Fraction for Two-Region Composite Sol id without Trapping versus Square-Root of Time . . . . . 34

8 Concentration Profile for Two-Region Composite Solid without Trapping for $D_{1}=10^{-13} \mathrm{~cm}^{2} \mathrm{sec}^{-1}$ and $D_{2} / D_{1}=1$

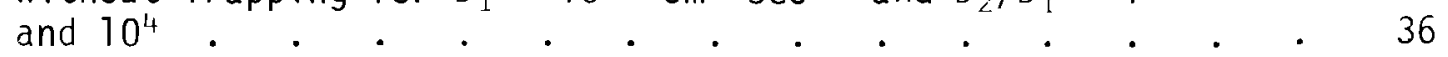

9 Geometry for Infinitesimally Thin Source Coupled to Semi-Infinite Sample . . . . . . . . . . 38

10 Geometry for Semi-Infinite Alpha-Particle Source . . . . 40

11 Calculated Helium Concentration Profile for Aluminum Coupled to Semi-Infinite Alpha Source with $N(E) \sim \sqrt{E}$ and $E_{\max }=5.5 \mathrm{MeV}$. Experimental results were used for $R(E)$. . max . . .

$\underline{\text { TABLE }}$

1 Stages of Helium Release . . . . . . . . . . . 12 
BNWL-2002

\subsection{INTRODUCTION}

The influence of inert gases on radiation damage in nuclear materials has been of continuing interest both from an engineering viewpoint and in fundamental studies of defects in solids. Gas release measurements can serve as an effective probe of radiation induced defects, since diffusion will be strongly affected, if not controlled, by trapping at various defects ranging from simple vacancies or interstitials to macroscopic bubbles in ceramic materials, inert gas diffusion in $\mathrm{UO}_{2}$ fuels and helium diffusion in $\alpha$-emitting, actinide heat sources are the major examples of application where continued studies of fundamental behavior are needed. Materials subject to helium production through $(n, \alpha)$ reactions and fusion system wall materials or electrodes also require an understanding of gas diffusion-defect interactions.

The main purpose of this report is to discuss the theory of gas release from solids. We are particularly interested in formulating an approach to interpreting helium release data for a solid which has been subjected to alpha-particle bombardment. It is assumed that the $\alpha$-particle source is $\mathrm{PuO}_{2}$ and that the initial helium concentration profile--which is identical to the alpha particle distribution within the solid--is to be determined experimentally. The problem of calculating the initial helium profile is discussed, and the theoretical treatments for several boundary conditions are considered, including a multi-region composite solid with reversible and irreversible trapping. 


\subsection{EXPER IMENTAL APPROACH}

Most He-release investigations have been carried out with ion accelerators. Ions having an energy from a few keV to $50 \mathrm{MeV}$ are utilized. Typically, irradiation is done with a monoenergetic beam. As a result, the initial helium concentration approximates a plane source located at a depth equal to the $\alpha$-particle range. Emphasis is often placed on bubble formation and release since very energetic He ions and very large ion doses $\left(10^{17}\right.$ to $10^{18}$ $\mathrm{cm}^{-2}$ ) are utilized.

He release studies are aiso done by recoil labeling samples. For example, a thin layer of ${ }^{226} \mathrm{Ra}$ can be applied to a sample, and during $\alpha$-decay the daughter product ${ }^{222} \mathrm{Rn}$ is recoiled into the solid. A sample can also be embedded in a matrix of fissioning $\mathrm{UO}_{2}$ to obtain recoiling inert gases $X e$ and $\mathrm{Kr}$. In addition to fission processes, $(p, \alpha)$ reactions can be utilized to obtain particle fluxes. Helium diffusion in aluminum has been studied by bombarding $A 1$ foils with $150 \mathrm{MeV}$ protons to utilize a $(p, \alpha)$ reaction with aluminum to dope samples with helium.

Another approach consists of introducing helium by coupling an alpha source to a sample. The initial helium concentration profile obtained in this manner is the same as that resulting from recoil labeling, assuming the identical source thicknesses. Helium release studies involving alpha sources is the approach of primary interest in this report. The use of alpha sources has obvious advantages over methods based on accelerators or recoil labeling. Apparently, this method has not been utilized very often in the past. One study involving an alpha source is described in Reference 1.

After doping materials with helium (or another inert gas), samples are heated and gas release monitored with a mass spectrometer. The quantity most often reported is fractional release $F(t)$. This quantity is simply the ratio of the accumulated amount of gas released to the total amount of gas contained in the sample initially. The total amount of gas can be determined by melting the sample. This can either be done at the end of an annealing run, or by melting an identical sample to one for which gas 
release data has been obtained. The measured quantity $F(t)$ can be related to diffusion phenomena and possibly to the nature of radiation damage in the sample.

A theoretical expression for $F(t)$ is obtained by calculating the concentration of gas in the sample as a function of depth $(x)$ and time $(t)$. Consider a sample in the form of a slab of thickness $W$. Let $c(x, t)$ denote the concentration of helium per $\mathrm{cm}^{3}$ at a point $x$ and time $t$. Then, the total amount of gas still remaining in a solid at time $t$ is given by

$$
c^{i n t}(t)=\int_{0}^{W} c(x, t) d x
$$

The notation "int" denotes integrated. If the initial concentration is given by $c_{0}(x)$, then the total amount of gas initially residing in the sample is given by

$$
c_{0}^{i n t}=\int_{0}^{W} c_{0}(x) d x
$$

The fractional release is determined from

$$
F(t)=1-\frac{c^{i n t}(t)}{c_{0}^{i n t}}
$$

To calculate $F(t)$, one must obtain $C(x, t)$ by solving the appropriate diffusion problem, and then determining $C^{i n t}(t)$.

Two kinds of release experiments are utilized: $F(t)$ is measured versus time for a fixed temperature; $F(t)$ is measured versus temperature with $T$ changing in a prescribed manner with time. In the latter case, $T$ is usually increased linearly with time. Figure 1 indicates the manner in which $F(t)$ versus time is presented. Typically, $F(t)$ is calculated for small $t$ and used to determine a diffusion coefficient, D. Similar data are obtained for different temperatures, and $D$ is determined versus $T$. One then tries to fit 
$D$ versus $T$ with an Arrhenius plot, i.e., in the form of $D=D_{0} \exp \left(\frac{-\Delta E}{k T}\right)$, where $D_{0}$ is the frequency factor in $\mathrm{cm}^{2} \mathrm{sec}^{-1}$, and $\Delta E$ is an activation energy. In the second case, $\frac{d F}{d T}$ is calculated and plotted versus $T$. Figure 2 illustrates the kind of results obtained. Maxima will occur in the release rate if dominant release mechanisms are separated in temperature adequately. An attractive approach involves determining $\frac{d F}{d T}$ versus $T$ to identify temperature ranges for interesting effects, and then carry out isothermal anneals. The theoretical problem for a linearly increasing $T$ involves solving the diffusion problem as in the isothermal case, but with a time varying $D$. The usual approach consists of determining expressions relating $T_{m}$ and $\Delta E$, where $T_{m}$ are values of temperature where maxima occur in $\frac{\mathrm{dF}}{\mathrm{dT}}$. 


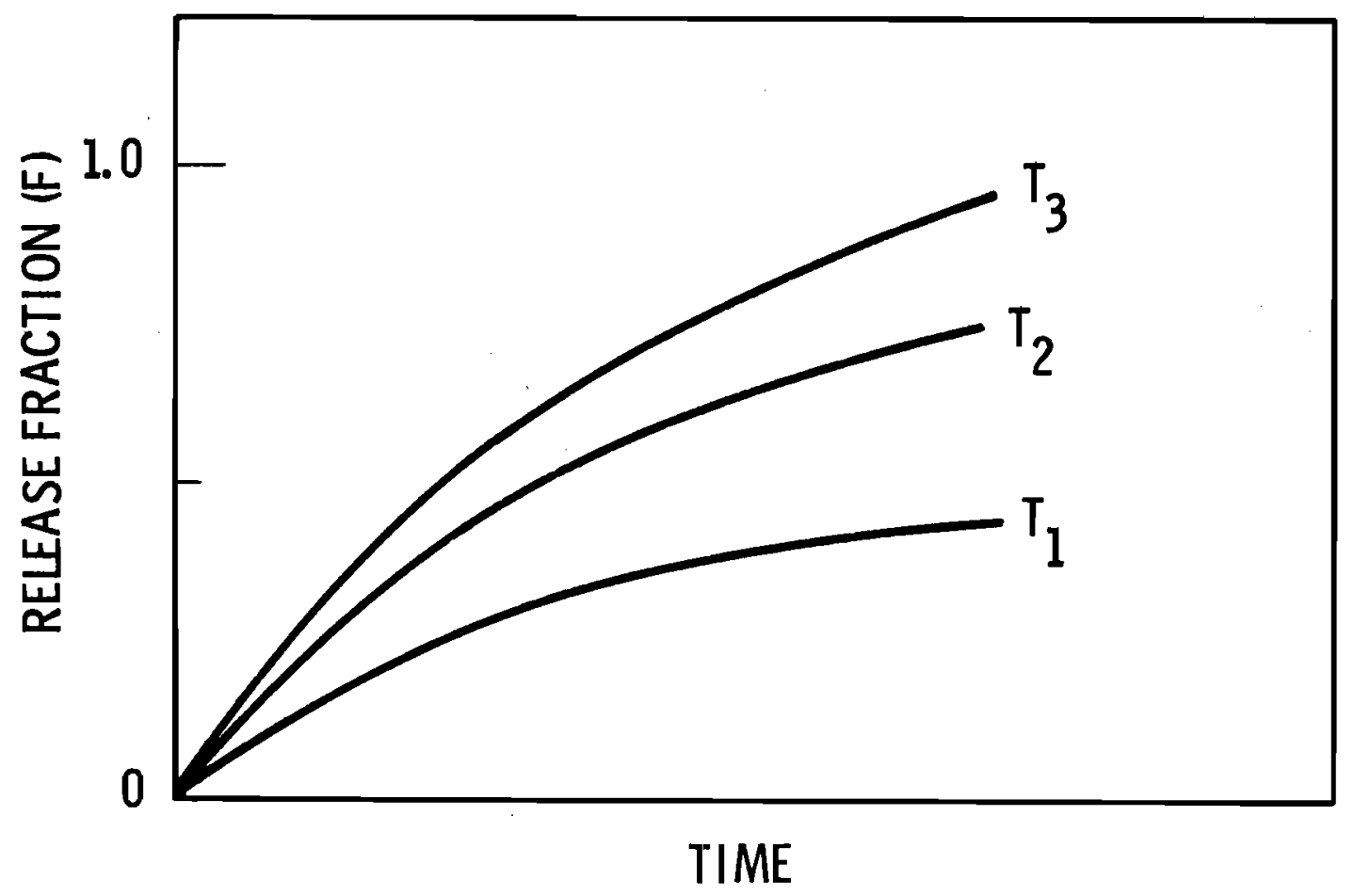

FIGURE 1. Typical Approach to Presenting Gas Release Data for Isothermal Anneal.

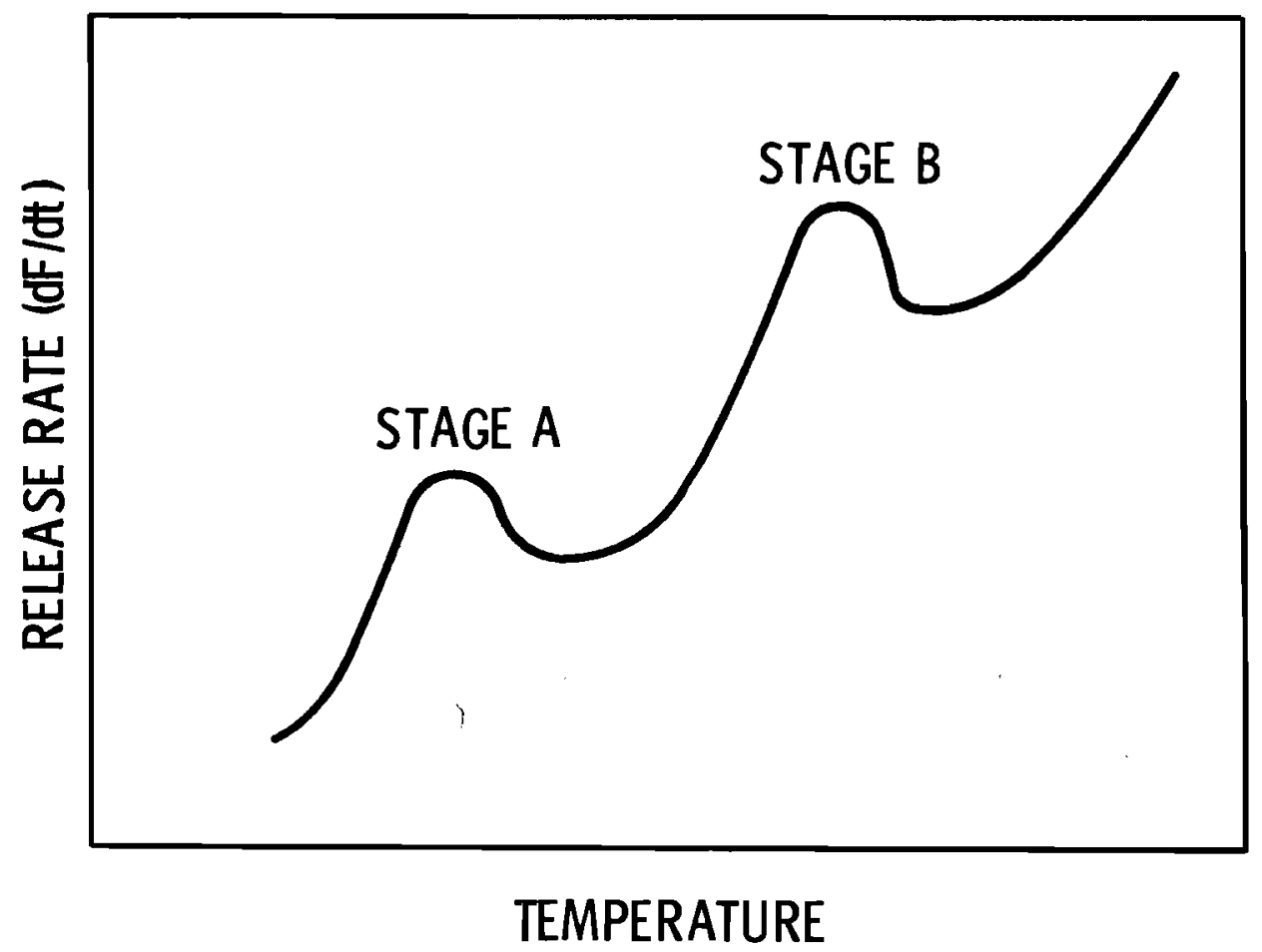

FIGURE 2. Typical Approach to Presenting Gas Release Data for Case of Temperature Increasing Linearly with Time. 


\subsection{OVERVIEW OF PREVIOUS INERT GAS RELEASE STUDIES}

Inert gas release studies can be distinguished by the method of injecting the inert gas atoms. The most common approaches have involved fission recoil and ion bombardment. The leader in studies based on fission recoil doping appears to be T. S. Elleman of the Nuclear Engineering Department, North Carolina State University. R. Kelly and H. Matzke have either worked together or separately in numerous studies based on doping by ion bombardment. After discussing the work of these researchers, general results obtained by other workers will be considered.

\subsection{ELLEMAN'S STUDIES}

El leman and co-workers have examined inert gas diffusion in ceramic oxides, alkali-metal iodides, $\mathrm{CaF}_{2}$ and $\mathrm{UO}_{2}$, and tritium diffusion in metals. The inert gas studies have primarily involved observation of gas release after implanting ${ }^{133}$ Xe by fission recoil or by doping with ${ }^{133} \mathrm{I}$ in the case of metal-iodides. Theory of gas release has been developed for several appropriate problem conditions. Tritium gas diffusion and release studies constitute Elleman's current efforts.

In Reference 2, xenon diffusion in single crystals of several ceramic oxides is discussed. In particular, results are presented for $\alpha-\mathrm{Al}_{2} \mathrm{O}_{3}, \mathrm{BeO}, \mathrm{MgO}$ and $\mathrm{ZrO}_{2}$ single crystals. ${ }^{133}$ Xe was injected into samples by fission recoil; oxide crystals are placed in contact with $\mathrm{U}_{2}$ during neutron irradiation. Typically, a fluence of $\sim 10^{13}$ fission fragments $/ \mathrm{cm}^{2}\left(\mathrm{ff} / \mathrm{cm}^{2}\right)$ was utilized. Release fraction results showed a rapid rise to $F \approx 0.001$ in the first few minutes, and then increased at a slower rate with $F \propto \sqrt{t}$. The initial rise was probably due to so-called damage diffusion. Elleman estimated that the xenon released during this initial stage would be expected to come from a surface layer $\approx 1000 \AA$ thick. Gas release after the initial rise could be interpreted in terms of classical diffusion. 
Studies of alkali-metal iodides ${ }^{3,4,7}$ involved the use of ${ }^{133}$ I and recoil injection of 133 Xe. Results discussed in Reference 4 are particularly interesting. CsI crystals were grown by Czochralski or modified Bridgman technnique. ${ }^{133}$ Xe was introduced in several ways. A uniform distribution was achieved by doping crystals with ${ }^{133}$ I, which decays to ${ }^{133}$ Xe by $\beta$-decay with a $20.8 \mathrm{hr}$ half-1ife. Other methods of introducing xenon involved fission recoil and the use of fast neutron reaction ${ }^{133} \mathrm{Cs}(n, p){ }^{133} \mathrm{Xe}$. Xenon was also introduced by maintaining a partial pressure above the melt during crystal growth. Concentrations of 1 to $5 \mathrm{ppm}$ can be obtained this way. Elleman also introduced natural defects, in the form of excessive strains, by altering crystal growth parameters. Some of the conclusions made by Elleman after analyzing gas release data were:

(1) classical diffusion of xenon occurs in CsI if the Xe concentration is uniform and $<5 \times 10^{14} \mathrm{~cm}^{3}$ and if perturbing effects such as grain boundaries and radiation damage are absent; (2) Xe introduced by fission recoil obeys classical diffusion if the dose is $\tilde{<} 3 \times 10^{12} \mathrm{ff} / \mathrm{cm}^{2}$ and exhibits trapping effects if the dose is $>3 \times 10^{13} \mathrm{ff} / \mathrm{cm}^{2}$; (3) trapping also occurs when the CsI crystals are significantly strained; (4) at rare gas concentrations in the range of one ppm and greater, trapping effects occur which appear to result from gas atom clustering; (5) xenon diffusion appears to be more compatible with a divacancy diffusion mechanism than with simple interstitial or vacancy diffusion.

Gas release measurements with $\mathrm{CaF}_{2}$ and $\mathrm{UO}_{2}$ single crystals ${ }^{8}$, gave similar results. ${ }^{133} \mathrm{Xe}$ was injected by fission recoil technique. Classical diffusion appears to occur for doses $\approx 10^{11} \mathrm{ff} / \mathrm{cm}^{2}$ and trapping phenomena are evident for doses $>10^{12} \mathrm{ff} / \mathrm{cm}^{2}$. In both cases, analysis of data was based on a model involving a uniform distribution of traps. This model would not seem appropriate if one assumes traps are due to radiation damage. 
Elleman and co-workers have developed expressions for release fraction for two important cases. In Reference 5, release of inert gas from a slab containing a uniform distribution of traps is considered assuming reversible trapping, and an initial concentration profile of the form $C_{0}\left(1-\frac{X}{R}\right)$ where $C_{0}$ is a constant and $R$ is the range of recoil injected xenon. In Reference 10, a two-region solid is considered. It is assumed that there is no trapping and that the initial concentration profile is the same as in the reversible trapping case.

Elleman's recent efforts involve tritium diffusion and gas release. Thin oxide films appear to impede tritium gas release. Elleman has also examined the theoretical problem for a single medium having a thin surface layer which impedes gas release.

\subsection{MATZKE AND KELLY'S STUDIES}

Matzke, Kelly and co-workers have also contributed significantly to the literature concerning gas release phenomena. Their experimental efforts have concentrated on gas release from solids after being bombarded with low energy inert-gas atoms. Both Kelly and Matzke have also examined theoretical problems. Their theoretical efforts generally involve attempts to solve a pertinent diffusion problem exactly.

In Reference 11, Kelly and Matzke examine the diffusion problem (gas release calculation) for several initial concentration profiles in a semiinfinite solid. In particular, initial concentrations given by $e^{-x}, x e^{-x}$ and a plane source are considered. Cases for no trapping and permanent trapping are discussed. Expressions for fractional release versus time assuming the temperature changes with time are also presented.

Gas release from samples which have been bombarded with inert gas atoms by a recoil process is considered in Reference 12. Two sample configurations are considered, namely, a slab and spherical geometry. Attention is given to the initial concentration profile. The profiles resulting from slab and spherical samples coupled to a semi-infinite and infinitesimal 
source are derived. It is assumed that ions lose energy in a medium in a linear fashion. As a result, the initial concentration in a slab after being coupled to a semi-infinite source is found to be

$$
C_{0}(x)=\left\{\begin{array}{cc}
(\text { Const. })\left(1-\frac{x}{R}\right) & 0 \leq X \leq R \\
0 & x \geq R
\end{array}\right.
$$

and for an infinitesimally thin source,

$$
C_{0}(x)=\left\{\begin{array}{cr}
\text { (Const.) } & 0 \leq x \leq R \\
0 & x \geq R
\end{array}\right.
$$

Note that in the case of a semi-infinite source, a linearly decreasing profile results. This behavior is a result of the linear energy loss assumption. A more general discussion of the problem will be presented in Section 5. Experimental results for ${ }^{133} \mathrm{Xe}$ bombarded $\mathrm{CaF}_{2}$ single crystals are explained fairly well.

One of the most interesting articles concerns the stages of helium release from a sample. ${ }^{13}$ However, it must be noted that this work is primarily based on experimental results obtained by bombarding materials with low-energy inert-gas ions in the 1 to $50 \mathrm{KeV}$ range. As a result, al1 referenced experimental data for release fraction relates to cases for which the initial gas concentration exists in the first $100 \mathrm{~A}$ to $1000 \mathrm{~A}$.

Kelly identified five stages of release. Two of these, IA and IB, occur well below the normal rnage for self diffusion in the particular solid. Stages IIA and IIB appear in same range as self diffusion. Stage III involves bubble migration and release, and is dominant well above the range of self diffusion.

Stage IA is described as any gas release occurring well below the temperature of both volume self diffusion and annealing of bombardment induced disorder. Gas release in this stage is apparently due to gas atoms in high mobility sites, such as divacancies or interstitial sites for metals. Kelly indicates that Stage IA release is most prominent at low doses and low bombardment energies. 
The theoretical description of Stage IA release involves the assumption that there are traps for the gas atoms. In fact, one must view normal substitutional sites and defect traps both as "permanent traps." The theoretical problem then consists of determining the concentration $c(x, t)$ of gas atoms in the "mobile" sites in the presence of these permanent traps and then calculating the fractional release.

Stage IB release occurs near the temperature range where bombardment disorder is annealed. Ideally, one determines this temperature range independently. This stage occurs below the range of self diffusion and is most prominent at high doses. The origin of gas release is thought to be a "sweepingout" of gas during the annealing of bombardment induced disorder. This mechanism is the so-called damage diffusion process. Kelly develops a simple model for Stage IB release. Essentially the same approach is used to discuss damage diffusion in Section 4 . The key feature in the damage diffusion model is that atoms are released in a one-step process. Whereas the release fraction increases as $t^{\frac{1}{2}}$ for small $t$ when ordinary diffusion is the driving force, $F(t) \sim t$ when damage diffusion occurs.

Stage IIA release occurs in the temperature range appropriate for normal self diffusion. It is most prominent at low doses. Gas release is attributed to atoms in substitutional sites. In the case of alkali halides, divacancies apparently play a role in self diffusion--thus, it is assumed that divacancies play a role in Stage IIA release from those materials. Normal diffusion theory is utilized for analysis of data.

Stage IIB occurs at slightly higher temperatures than IIA. It is most prominent at moderate doses. The release mechanism is thought to involve normal diffusion (as in IIA), but with weak trapping. Weak trapping can be due to gas-gas or gas-damage interactions. Theory must provide for a finite probability for detrapping, that is, for reversible trapping.

In general, Stage III refers to gas release at temperatures well above the volume self-diffusion range. In most cases, release is attributed to the motion of gas-filled bubbles. Stage III becomes more prominent with higher doses. It is generally assumed that regular diffusion theory can 
be used with the diffusion coefficient becoming $D_{\text {Bubble }}$. Trapping of bubbles can occur at dislocations, grain boundaries or precipitates and can therefore have an associated $L$ or diffusion length. In order to treat bubble release, one must determine the initial bubble concentration. The initial bubble concentration is related to the amount of trapped inert gas at lower temperatures.

Although Kelly's five stages of gas release were deduced from lowenergy ion bombardment experiments, similar models should apply to gas release experiments carried out after higher energy ion bombardment. Regardless of the ion energy, we can expect some initial gas release due to damage diffusion or "Stage IA" type of release, if the dose is high enough. In the case of low-energy ions, the release phenomea involve only a thin surface layer. If these release pheonomena are observed in the case of more penetrating ions, then a larger portion of the sample is involved. Stage IA is simply a case of diffusion with permanent trapping. However, diffusion occurs via high mobility sites; thus, if a Stage IA occurs, there must be a Stage II at higher temperatures involving diffusion along normal atomic sites, or interstitial sites.

Damage diffusion is exhibited when enough damage has occurred that a large number of atoms can be released by a one-step process. In the case of high energy ion implants, the sample would have to be significantly damaged over the range of the bombarding particles.

Kelly also has examined a composite solid problem. ${ }^{14}$ A two region system is considered. Normally, one assumes

$$
\begin{aligned}
& c_{1}(x, t)=c_{2}(x, t) \\
& D_{1} \frac{\partial^{C} 1}{\partial x}=D_{2} \frac{\partial^{C_{2}}}{\partial x}
\end{aligned}
$$

at a boundary separating two regions. Kelly claims that if $D_{1}$ and $D_{2}$ are different one should impose $D_{1} C_{1}=D_{2} C_{2}$ instead of $C_{1}=C_{2}$. He supposes that $D_{1}$ and $D_{2}$ are different because of different trap depths. This is confusing. $D_{1}$ and $D_{2}$ refer to diffusion of the gas atom along normal paths, 
TABLE 1. Stages of Helium Release

\begin{tabular}{|c|c|c|c|c|}
\hline Stag & $\begin{array}{l}\text { Irradiation } \\
\text { Conditions }\end{array}$ & $\begin{array}{c}\text { Temperature } \\
\text { Range }\end{array}$ & $\begin{aligned} & \text { Nature } \\
\text { of } & \text { Diffusion }\end{aligned}$ & $\begin{array}{l}\text { Status } 01 \\
\text { Theory }\end{array}$ \\
\hline
\end{tabular}

\begin{tabular}{|c|c|c|c|c|}
\hline IA & $\begin{array}{l}\text { Low Doses \& } \\
\text { Low ion } \\
\text { Energies }\end{array}$ & $\begin{array}{l}\text { Well below } \\
\text { range of } \\
\text { volume self } \\
\text { diffusion } \\
\& \text { range of } \\
\text { bombardment } \\
\text { annealing }\end{array}$ & $\begin{array}{l}\text { Gas atoms in } \\
\text { high mobility } \\
\text { sites. }\end{array}$ & $\begin{array}{l}\text { Described by } \\
\text { normal dif- } \\
\text { fusion theory } \\
\text { with permanent } \\
\text { trapping. }\end{array}$ \\
\hline IB & High Doses & $\begin{array}{l}\text { Range of } \\
\text { annealing of } \\
\text { bombardment } \\
\text { induced } \\
\text { disorder. }\end{array}$ & $\begin{array}{l}\text { So-called } \\
\text { damage diffu- } \\
\text { sion involving } \\
\text { one-step } \\
\text { processes }\end{array}$ & $\begin{array}{l}\text { Described by } \\
\text { single jump pro- } \\
\text { cess with one or } \\
\text { a spectrum of } \\
\text { activation } \\
\text { energies. }\end{array}$ \\
\hline I IA & Low Doses & $\begin{array}{l}\text { Range Typ- } \\
\text { ical of vol- } \\
\text { ume self } \\
\text { diffusion. }\end{array}$ & $\begin{array}{l}\text { Gas diffuses } \\
\text { through sites } \\
\text { as in self } \\
\text { diffusion. }\end{array}$ & $\begin{array}{l}\text { Normal diffusion } \\
\text { theory with } \\
D_{\text {Gas }} \approx D_{\text {Self- }} \\
\text { Diff. }\end{array}$ \\
\hline I IB & $\begin{array}{l}\text { Moderate } \\
\text { Doses }\end{array}$ & $\begin{array}{l}\text { Slightly } \\
\text { higher tem- } \\
\text { peratures } \\
\text { than IIA. }\end{array}$ & $\begin{array}{l}\text { Normal Diffu- } \\
\text { sion as in IIA } \\
\text { but with weak } \\
\text { trapping. }\end{array}$ & $\begin{array}{l}\text { Theory not very } \\
\text { wel1 developed }\end{array}$ \\
\hline I I I & High Doses & $\begin{array}{l}\text { Well above } \\
\text { that of } \\
\text { self diffus- } \\
\text { ion. }\end{array}$ & $\begin{array}{l}\text { Due to migra- } \\
\text { tion of gas- } \\
\text { filled } \\
\text { bubbles. }\end{array}$ & $\begin{array}{l}\text { Generally assumed } \\
\text { that regular dif- } \\
\text { fusion theory } \\
\text { applies with } \\
D_{\text {Bubble, etc. }}\end{array}$ \\
\hline
\end{tabular}


while "trapping" is a term usually reserved for situations for which an atom resides in a defect. In fact, Kelly examines the problem involving a homogeneous solid with trapping in the same paper. In this case, the parameter $D$ is clearly unrelated to trapping.

\subsection{OTHER WORK}

Two papers are particularly worth noting, namely, the work by Hurst ${ }^{15}$ and Gaus. ${ }^{16}$ These articles are often referenced and represent some of the first theoretical work regarding gas release in the presence of trapping. Earlier papers had considered gas release phenomena without trapping. ${ }^{17} 18$ Both Hurst and Gaus assumed a homogeneous distribution of traps and with the initial gas concentration also being uniform.

A considerable amount of experimental results are available concerning helium bubble diffusion release. Most of the reported studies have involved bombarding samples with high energy helium ions to large dose levels, and observing gas release at high temperatures. This subject will not be considered here in much detail. It should be noted, however, that nuclei for bubble formation are trapped helium atoms. Thus, in solving diffusion and gas release problems, determination of the trapped helium concentration relates to bubble studies. 


\subsection{THEORY OF INERT GAS RELEASE}

Calculation of gas release rates requires knowledge of gas concentration as a function of depth in the sample and time, namely, $c(x, t)$. Usually it is assumed that the initial concentration profile $C_{0}(x)$ is known, and $c(x, t)$ is calculated by considering diffusion of the gas into the solid and release of gas at the surfaces. $F(t)$ is then calculated according to (3). In the following sections we consider the general approach to determining $c(x, t)$, the solutions to relatively simple problem geometries are given, problems involving composite solids are examined, and the formulation of a numerical approach and the corresponding computer code are discussed.

\subsection{GENERAL APPROACH TO DIFFUSION PROBLEM}

Consider a slab of material of width $W$ with an initial concentration of inert gas, $C_{0}(x)$. Assuming that no trapping of gas atoms occurs, the diffusion of this gas is described by

$$
\frac{\partial C(x, t)}{\partial t}=D \frac{\partial^{2} C(x, t)}{\partial x^{2}}
$$

where $D$ is the diffusion coefficient. $D$ can usually be expressed as

$$
D=D_{0} \exp \left(\frac{-\Delta E}{k T}\right)
$$

where $D_{0}$ is a constant and $\Delta E$ is an activation energy. Assuming that the sample is in vacuum, the appropriate boundary conditions are

$$
\begin{aligned}
& C(x=0, t)=0 \\
& C(x=w, t)=0
\end{aligned}
$$

In many gas release experiments, trapping of gas atoms can occur in the bulk region. In general, one must also assume there is a finite probability that an atom can be released from a trap. Thus, a general problem 
involves "reversible trapping." In this case, $c(x, t)$ is determined by solving two simultaneous differential equations, namely,

$$
\begin{aligned}
& \frac{\partial C(x, t)}{\partial t}=0 \frac{\partial^{2} C(x, t)}{\partial x^{2}}-\frac{\partial m(x, t)}{\partial t} \\
& \frac{\partial m(x, t)}{\partial t}=k C(x, t)-k^{\prime} m(x, t)
\end{aligned}
$$

where,

$$
\begin{aligned}
m(x, t) & =\text { Concentration of inert gas atoms in traps } \\
k & =\text { Rate constant regarding trapping of diffusing inert gas atoms } \\
k^{\prime} & =\text { Rate constant regarding detrapping of inert gas atoms }
\end{aligned}
$$

It should be noted that

$$
\begin{aligned}
& k=\tau^{-1} \\
& k^{\prime}=\tau^{\prime-1}
\end{aligned}
$$

where $\tau$ is the average lifetime of a diffusion atom before it is trapped, and $\tau^{\prime}$ is the average amount of time spent by an atom in a trap.

The case referred to as "permanent trapping" is straightforward. Permanent trapping implies $\tau^{\prime} \rightarrow \infty$, or $k^{\prime}=0$. Thus, once an atom is trapped, it stays there. Then

$$
c(x, t)=e^{-k t} C^{\prime}(x, t)
$$

where $C^{\prime}(x, t)$ satisfies

$$
\frac{\partial C^{\prime}}{\partial t}=D \frac{\partial^{2} C^{\prime}}{\partial x^{2}}
$$

The concentration of atoms in traps, $m(x, t)$, is given by

$$
m(x, t)=m(x, 0)+k[C(x, 0)-C(x, t)]
$$

Analysis of gas release studies is usually based on solutions to the appropriate diffusion problem obtained by Laplace transform technique, or 
by the use of a Green's function. The solution for $C(x, t)$ is invariably in the form of an infinite series. The problem which appears to be of most interest is that of a solid having two regions with different diffusion coefficients, and different values for $k$ and $k^{\prime}$. The first layer would represent a region of damage, and the second layer would represent the undamaged material. For this problem, it definitely appears best to utilize numerical techniques to determine $c(x, t)$. A computer code based on a numerical approach is also desirable in the case of more simple problem geometries, since $C_{0}(x)$ and boundary conditions can be varied without the necessity of solving the problem over again.

\subsection{PROBLEMS FOR A HOMOGENEOUS SOLID}

\subsubsection{Semi-Infinite Solid Without Trapping}

Consider the problem described by Figure 3, namely, a slab of thickness $w$ containing inert gas at $t=0$ with an arbitrary concentration profile, $C_{0}(x)$. In particular, we consider the case of $w \rightarrow \infty$. If it is desirable to keep $C_{0}(x)$ arbitrary then it is convenient to use a Green's function approach, or solve the problem numerically. Let us consider using a Green's function solution.

We define a function $g\left(x, x^{\prime} ; t\right)$ which gives the proper concentration profile at $x$ and $t$ for the case of an initial concentration profile described by a spike located at $x^{\prime}$. This concept is discussed further in Appendix $I$. As indicated there, the solution $C(x, t)$ for a case where $C_{0}(x)$ is the initial profile is given by

$$
C(x, t)=\int_{0}^{\infty} c_{0}\left(x^{\prime}\right) g\left(x, x^{\prime}, t\right) d x^{\prime}
$$

The integrated concentration is given by

$$
\begin{aligned}
c^{\text {int }}(t) & =\int_{0}^{\infty} d x\left\{\int_{0}^{\infty} d x^{\prime} C_{0}\left(x^{\prime}\right) g\left(x, x^{\prime}, t\right)\right\} \\
& =\int_{0}^{\infty} d x^{\prime} C_{0}\left(x^{\prime}\right)\left\{\int_{0}^{\infty} d x g\left(x, x^{\prime}, t\right)\right\}
\end{aligned}
$$




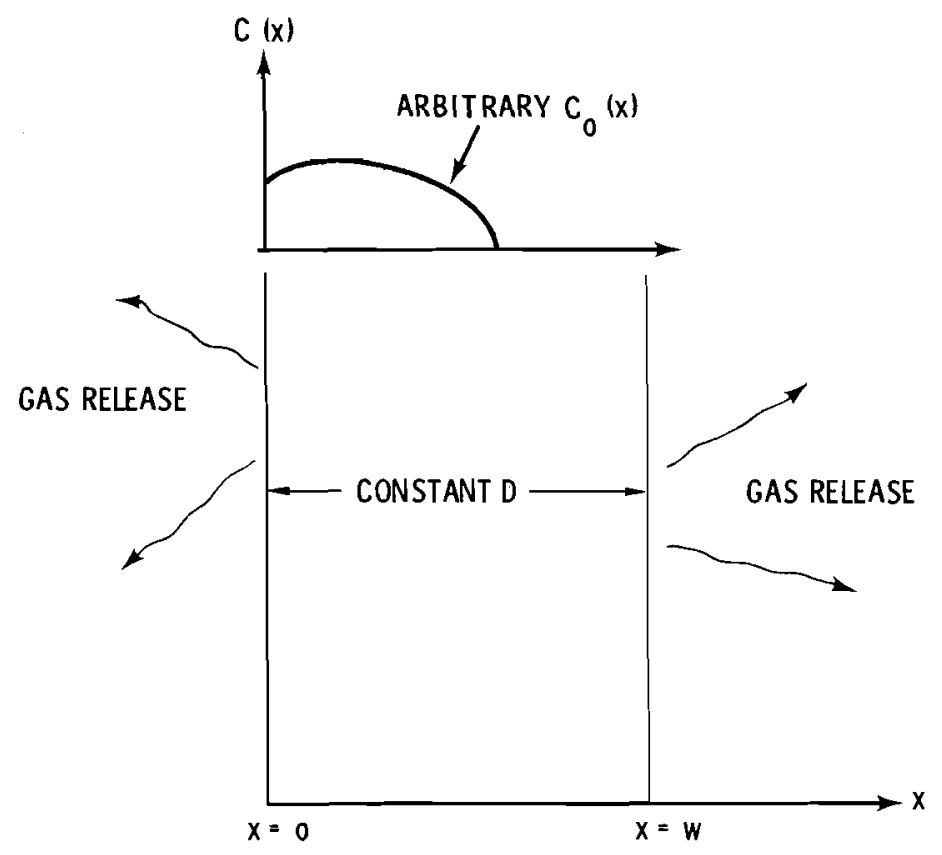

FIGURE 3. Problem Geometry for Solid of Thickness w. Arbitrary initial concentration $C_{0}(x)$ shown close to $x=0$ surface. If $w$ is large enough that no gas atoms reach $x=w$ surface during time of experiment, then one can view solid as semi-infinite.

The Green's function for a semi-infinite solid is

$$
g\left(x, x^{\prime}, t\right)=\frac{1}{2 \sqrt{\pi D t^{\prime}}}\left\{\exp \left[\frac{\left(x-x^{\prime}\right)^{2}}{4 D t}\right]+\exp \left[\frac{\left(x+x^{\prime}\right)^{2}}{4 D t}\right]\right.
$$

Substituting (15) into (14), we find

$$
c^{i n t}(t)=\int_{0}^{\infty} c_{0}\left(x^{\prime}\right) \operatorname{erf}\left(\frac{x^{\prime}}{2 \sqrt{D t}}\right) d x^{\prime}
$$


The well known result that $F(t) \sim \sqrt{D t}$ for small $t$ can be derived for an arbitrary $C_{0}(x)$, as long as $C_{0}(x) \neq 0$ only over a finite range of $x$. Utilizing

$$
\begin{aligned}
& \operatorname{erf}(y) \simeq 1-\frac{1}{\sqrt{\pi}} \frac{e^{-y^{2}}}{y} \\
& \text { for } y>>1,
\end{aligned}
$$

we find that

$$
c^{i n t}(t)=c^{i n t}(t=0)-2 \sqrt{\frac{D t}{\pi}} \int_{0}^{\infty} \frac{C_{0}(x) e^{-\left(\frac{x}{2 \sqrt{d} t}\right)^{2}} d x}{x}
$$

$F(t)$ is given by

$$
\begin{aligned}
& F(t)=1-\frac{c^{i n t}(t)}{c^{i n t}(t=0)} \\
& F(t) \simeq 2 \sqrt{\frac{D t}{\pi}}\left[\int_{0}^{\infty} C_{0}(x) \exp \frac{\left(\frac{-x^{2}}{4 D t}\right)}{x} d x\right]
\end{aligned}
$$

\subsubsection{Semi-Infinite Solid with Surface Transfer Coefficient}

This problem is the same as that described in the previous section with the exception that the surface boundary condition is

$$
D\left(\frac{d C(x, t)}{d x}\right)_{x=0}=H(C(x, t))_{x=0}
$$


where $\mathrm{H}$ is the surface transfer coefficient. The Green's function is required to obey the same surface boundary condition. As indicated in Appendix I, the Green's function is found to be

$$
\begin{aligned}
g\left(x, x^{\prime} ; t\right) & =\frac{1}{2 \sqrt{\pi D t}}\left\{\exp \left[\frac{-\left(x-x^{\prime}\right)^{2}}{4 D t}\right]+\exp \left[\frac{-\left(x+x^{\prime}\right)^{2}}{4 D t}\right]\right\} \\
& -h \exp \left[D t^{2}+h\left(x+x^{\prime}\right)\right] \operatorname{erfc}\left\{\frac{x+x^{\prime}}{2 \sqrt{D t}}+h \sqrt{D t}\right\}
\end{aligned}
$$

where $h=H / D$.

Using the same procedure as in the previous section,

$$
c^{i n t}(t)=\int_{0}^{\infty} d x^{\prime} C_{0}\left(x^{\prime}\right)\left[\operatorname{erf}\left(\frac{x^{\prime}}{2 \sqrt{D t}}\right)+e^{h x^{\prime}+h^{2} D t} \operatorname{erfc}\left(\frac{x^{\prime}}{2 \sqrt{D t}}+h \sqrt{D t}\right)\right]
$$

If a particular initial concentration $C_{0}(x)$ is utilized, then it is often convenient to use the Laplace transform technique to solve the diffusion problem. Elleman and co-workers have done this for the present problem in the case of $c_{0}(x)$ being given by

$$
C_{0}(x)=\left\{\begin{array}{ll}
C_{0}\left(1-A_{0} x\right) & 0 \leq x \leq x_{1} \\
C_{1}\left(1-A_{1} x\right) & x_{1} \leq x \leq x_{2}
\end{array}\right\}
$$

where $C_{0}, C_{1}, A_{0}$ and $A_{1}$ are constants. The analys is done by El leman in this case concerned tritium diffusion and release from niobium. The tritium was heavily concentrated near the surface initially, and the finite surface transfer coefficient was assumed to result from an oxide surface layer. 


\subsubsection{Slab With Reversible Trapping}

In this section, we consider diffusion and release of inert gas in a slab that contains traps, and for which the gas concentration profile is $C_{0}(x)$. A Green's function approach is not appropriate in this case because there are two coupled differential equations. A Laplace transform approach can be carried out, but it is more straight forward to utilize a series expansion method as done by Ong and Elleman in Reference 5 . It is more convenient to consider a slab geometry rather than semi-infinite solid in this case. Results for the semi-infinite solid are obtained by letting $w \rightarrow \infty$.

We will consider a more general case than Ong and Elleman did. They set $m(x, 0)=0$. We will let $m(x, 0)$ be finite. In addition, it will be assumed that both permanent traps and a reversible trap exist. The appropriate equations are

$$
\begin{aligned}
& \frac{\partial C}{\partial t}=D \frac{\partial^{2} C}{\partial x^{2}}-\frac{\partial m}{\partial t}-\frac{\partial M}{\partial t} \\
& \frac{\partial m}{\partial t}=K C-k^{\prime} m \\
& \frac{\partial M}{\partial t}=K C
\end{aligned}
$$

where $m(x, t)$ is the concentration of gas atoms in the reversible trap, and $M$ is the concentration of gas atoms in permanent traps. Note that $M$ can refer to a set of permanent traps. That is,

$$
\begin{aligned}
M & =\sum_{i} M_{i} \\
K & =\sum_{i} K_{i} \\
\frac{\partial M_{j}}{\partial t} & =K_{i} C
\end{aligned}
$$


The boundary conditions are

$$
\begin{aligned}
& C(0, t)=0 \\
& C(x, 0)=C_{0}(x) \\
& m(x, 0)=m_{0}(x) \\
& M(x, 0)=M_{0}(x)
\end{aligned}
$$

The various concentrations are written as

$$
\begin{aligned}
& c(x, t)=\sum_{n=1}^{\infty}\left[a_{n} e^{-\lambda n^{k t}}+a^{\prime} n^{-\lambda^{\prime} n^{k t}}\right] x \sin \left(\frac{n \pi x}{w}\right) \\
& m(x, t)=\sum_{n=1}^{\infty}\left[b_{n} e^{-\lambda n^{k t}}+b^{\prime}{ }^{\prime} e^{-\lambda^{\prime} n^{k t}}\right] \sin \left(\frac{n \pi x}{w}\right) \\
& M(x, t)=\sum_{n=1}^{\infty}\left[c_{n} e^{-\lambda n^{k t}}+c^{\prime}{ }^{n} e^{-\lambda{ }^{\prime} k t}\right] \sin \left(\frac{n \pi x}{w}\right)
\end{aligned}
$$

The constants $A_{n}, A^{\prime}{ }_{n}, B_{n}, B^{\prime}{ }_{n}, \lambda_{n}$ and $\lambda^{\prime}{ }_{n}$ are determined by substituting expressions for $C(x, t), m(x, t)$ and $M(x, t)$ into (23), (24) and (25). We find

$$
\begin{aligned}
& a_{n}=\frac{A_{n}\left[\lambda_{n}^{\prime} k-D\left(\frac{n \pi}{w}\right)^{2}-k\right]+k^{\prime} B_{n}}{k\left(\lambda_{n}^{\prime}-\lambda_{n}\right)} \\
& a_{n}^{\prime}=A_{n}-a_{n} \\
& b_{n}=\frac{\left[k+D\left(\frac{n \pi}{w}\right)^{2}-\lambda_{n} k\right]}{k^{\prime}} a_{n} \\
& b_{n}^{\prime}=B_{n}-b_{n} \\
& A_{n}=\frac{2}{w} \int_{0}^{w} C_{0}(x) \sin \left(\frac{n \pi x}{w}\right) d x
\end{aligned}
$$




$$
\begin{aligned}
B_{n}=\frac{2}{w} \int_{0}^{w} m_{0}(x) \sin \left(\frac{n \pi x}{w}\right) d x \\
\left.\begin{array}{c}
\lambda_{n} \\
\lambda_{n}^{1}
\end{array}\right\}=1 / 2\left\{\left(1+\frac{k^{\prime}}{k}+\left(\frac{n \pi}{w}\right)^{2} \frac{D}{k}\right)\right. \\
\pm\left[\left(1+\frac{k}{k}+\left(\frac{n \pi}{w}\right)^{2} \frac{D}{k}\right)^{2}-4\left(\frac{n \pi}{w}\right)^{2} \frac{D k^{\prime}}{k^{2}}\right]^{1 / 2}
\end{aligned}
$$

$M(x, t)$ is given by

$$
M(x, t)=M_{0}(x)+k \sum_{n}\left[\frac{a_{n}}{\lambda_{n} k}\left(1-e^{-\lambda_{n} k t}\right)+\frac{a_{n}^{\prime}}{\lambda_{n}^{\prime} k}\left(1-e^{-\lambda_{n}^{\prime} k t}\right)\right]
$$

The release fraction is calculated according to

$$
F(t)=1-\frac{{ }_{0} \int^{W}[C(x, t)+m(x, t)+M(x, t)] d x}{{ }_{0} \int^{W}\left[C_{0}(x)+m_{0}(x)+M_{0}(x)\right] d x}
$$

with

$$
{ }_{0} \mathcal{S}^{W} \mathrm{C}(\mathrm{x}, \mathrm{t}) \mathrm{dx}=\sum_{\substack{\text { odd } \\ n}}\left(\frac{2 w}{n \pi}\right)\left\{A_{n} e^{-\lambda_{n} t}+A^{\prime} n^{e^{-\lambda^{\prime}} n^{t}}\right\}
$$

and similarly for integrals over $m(x, t)$ and $M(x, t)$.

\subsection{THEORY OF DAMAGE DIFFUSION}

In this section, a formulation of the theory of gas release due to damage diffusion is presented. The approach is similar to that discussed in Reference 13 by Kelly and Jech. Their derivation was rather sketchy. Furthermore, an analys is was done only for an exponential initial concentration profile, and the time dependence of $F(t)$ was not examined. 
We assume gas atoms are released by a one-step process. In particular, it is assumed that inert gas atoms reside in radiation-induced traps, and can be released once an atom escapes the trap. Consider a semi-infinite sample which is partitioned into regions as shown in Figure 4 . Consider the concentration of gas in the $n$th partition, $c\left(x_{n}, t\right)=c_{n}(t)$. The change in $c_{n}(t)$ due to atoms being emitted from traps and then being released from the surface can be written as

$$
d c_{n}(t)=-C_{n}(t) P_{n} k_{1} \cdot d t
$$

where $k_{1}$ is the transition rate for gas atoms leaving a trap, and $P_{n}$ is the probability that an atom in the nth layer will be released to the surface once it has been emitted from a trap. The rate constant would be expected to be given by an expression such as

$$
k=k_{0} \exp \left(\frac{-\Delta E}{k T}\right)
$$

We assume that an emitted atom moves to the surface by passing through disordered material. Thus,

$$
\begin{aligned}
P_{n} & =\left(\begin{array}{l}
\text { Probability of } \\
\text { Atom Encountering } \\
\text { Disordered Region } \\
\text { In } n-1 \text { th Layer }
\end{array}\right) \cdot\left(\begin{array}{l}
\text { Probability of } \\
\text { Atom Encountering } \\
\text { Disordered Region } \\
\text { In } n-2 \text { th Layer }
\end{array}\right) \cdots \\
& =\left(\begin{array}{l}
\text { Volume of Disorder } \\
\text { In } n-1 \text { th Layer } \\
\text { Volume of } \\
n-1 \text { th Layer }
\end{array}\right) \cdots \\
& =\left(\frac{C_{0}\left(x_{n-1}\right) A(\Delta x) V_{d}}{A(\Delta x)}\right) \ldots \\
& =C_{0}\left(x_{n-1}\right) V_{d} \cdot C_{0}\left(x_{n-2}\right) V_{d} \cdots
\end{aligned}
$$

or 


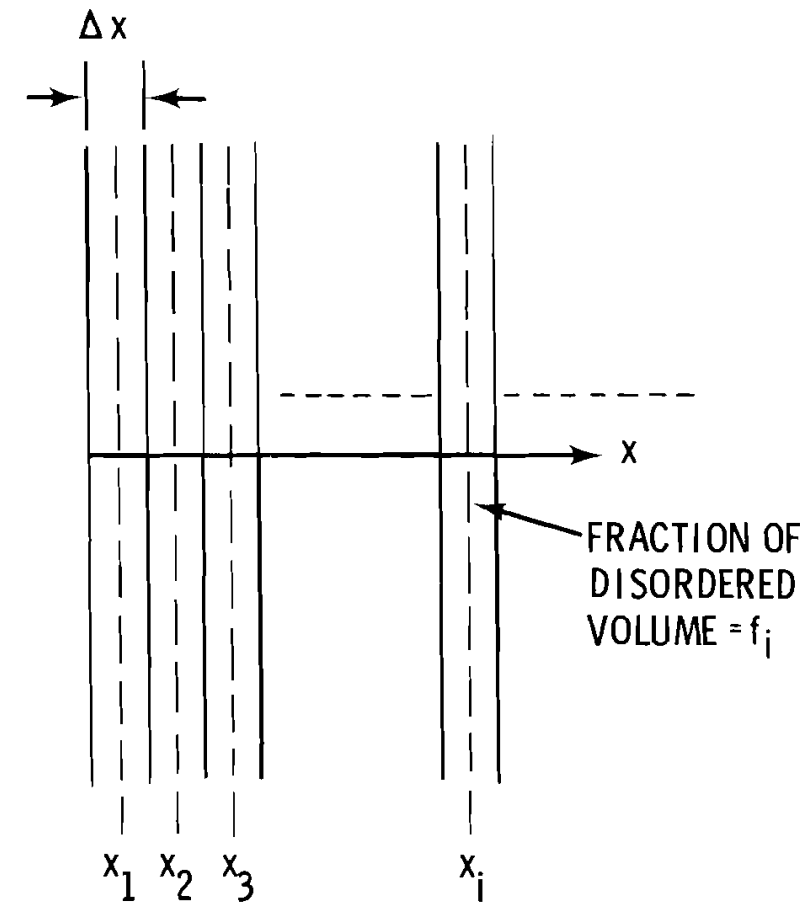

FIGURE 4. Partitioned Semi-infinite Solid Utilized in Kelly's Model for Calculating Gas Release during Annealing of Bombardment Disorder

$$
P_{n}=v_{d}^{n-1} \prod_{j=1}^{n-1} C_{0}\left(x_{j}\right)
$$

where we have assumed that the volume of disorder contributed by each gas atom is $V_{d}$ and is located where the atom comes to rest during the irradiation process. We assume $P_{n}$ and $k$ are not functions of time. Thus we have

$$
c_{n}(t)=c_{0}\left(x_{n}\right) \exp \left(-P_{n} k t\right)
$$

The release fraction is given by

$$
F(t)=1-\frac{\sum_{n=1}^{\infty} c_{n}(t)}{\sum_{n=1}^{\infty} c_{0}\left(x_{n}\right)}
$$


For small values of time $\left(t<<\left(P_{1} k\right)^{-1}\right)$,

$$
F(t) \approx 1-\frac{\sum_{n} C_{0}\left(x_{n}\right)\left[1-P_{n} k_{1} t\right]}{\sum_{n} C_{0}\left(x_{n}\right)}=\left[\frac{\sum_{n=1}^{\infty} C_{0}\left(x_{n}\right) P_{n}}{\sum_{n=1}^{\infty} C_{0}\left(x_{n}\right)}\right] k_{1} t
$$

The most important result in this derivation is that $F(t)$ at for small values of time in the case of gas release by damage diffusion.

The theoretical expression (43) for $F(t)$ is appropriate for gas release by a one-step process from a single type of trap. It appears that this result is the most general one developed for damage diffusion. Kelly and Jech did not examine $F(t)$ in detail. They estimated the asymptotic value of the release fraction. It is clear from (42) and (43) that for times not "short", and for arbitrary initial concentration profiles, the behavior of $F(t)$ can be quite complex.

\subsection{GAS RELEASE FROM A COMPOSITE SOLID}

The problem of most interest is the most complex. A composite solid refers to a system which has two or more regions with different diffusion characteristics. For example, consider a slab which has been irradiated with alpha particles on one side. If the alpha particle source is infinitely thin, then the initial concentration of helium will be a constant from the surface to a depth $R$, the alpha particle range, and zero for $X \geq R$. We would expect the density of displaced atoms to be approximately proportional to the initial helium concentration. If the radiation damage is extensive enough, then we would expect helium to diffuse differently in the surface region than in the bulk. Furthermore, trapping characteristics would be expected to be different in the two regions. 
Figure 5 defines the diffusion and gas release problem of interest. We assume an arbitrary initial gas concentration $C_{0}(X)$, and two regions with parameters as indicated. The symbol " $M$ " refers to permanent traps while " $m$ " refers to reversible traps. The differential equations and boundary conditions are:

\section{Differential Equations:}

$$
\begin{aligned}
& \frac{\partial C_{j}}{\partial t}=D_{j} \frac{\partial^{2} C_{j}}{\partial x^{2}}-\frac{\partial m_{j}}{\partial t}-\frac{\partial M_{j}}{\partial t} \\
& \frac{\partial m_{j}}{\partial t}=k_{j} C-k_{j}^{\prime} m_{j} \\
& \frac{\partial M_{j}}{\partial t}=k_{j} C_{j} \\
& j=1,2
\end{aligned}
$$

Boundary Conditions:

$$
\begin{aligned}
& C_{1}(x=0, t)=0 \\
& C_{2}\left(x=x_{2}, t\right)=0 \\
& C_{1}\left(x_{1}, t\right)=C_{2}\left(x_{1}, t\right) \\
& D_{1}\left(\frac{\partial C_{1}}{\partial x}\right)_{x=x_{1}}=D_{2}\left(\frac{\partial C_{2}}{\partial x}\right)=x_{1}
\end{aligned}
$$




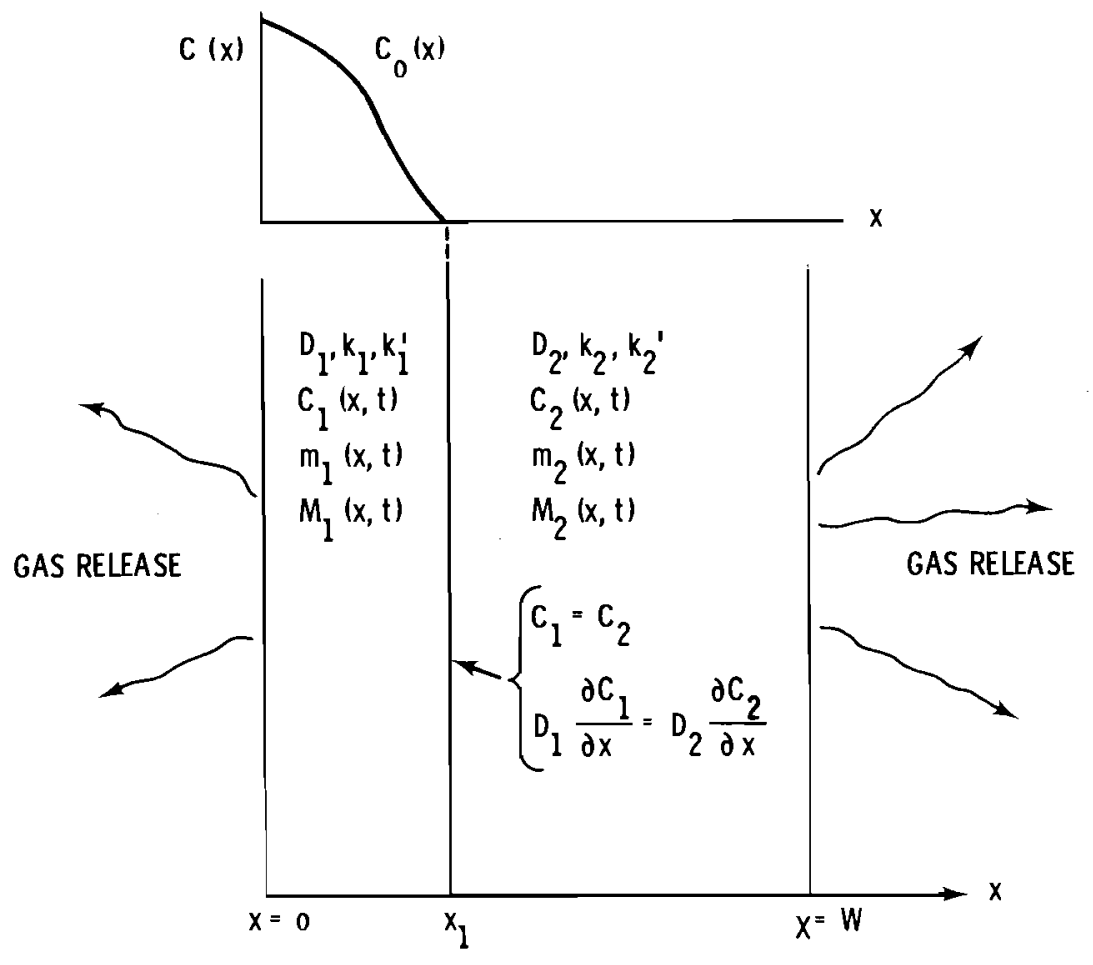

FIGURE 5. Geometry for Two-Region Composite Diffusion Problem

Solving composite-solid diffusion (or heat transfer) problems is a cumbersome task. Regardless which approach is taken, the solution involves an infinite series. In the following sections three approaches are briefly discussed namely, a Green's function approach, an eigenfunction expansion technique and a numerica 1 approach. On1y in the latter case, is the complete problem described by (45) through (48) treated.

\subsubsection{Composite Semi-Infinite Solid without Trapping by Green's Function}

This problem is treated in detail in Appendix II. A Green's function is defined for regions 1 and 2 , such that the concentration profile in each region is given by

$$
c_{1}(x, t)=\int_{0}^{\infty} c_{0}\left(x^{\prime}\right) g_{1}\left(x, x^{\prime} ; t\right) d x^{\prime}
$$


and

$$
c_{2}(x, t)=\int_{0}^{\infty} c_{0}\left(x^{\prime}\right) g_{2}\left(x, x^{\prime} ; t\right) d x^{\prime}
$$

The integrated concentration is found to be

$$
\begin{aligned}
c^{\text {int }}= & \frac{1}{2} \int_{0}^{\infty} d x^{\prime} C_{0}\left(x^{\prime}\right)\left[\operatorname{erf}\left(\frac{x_{1}-x^{\prime}}{2 \sqrt{D_{1} t}}\right)-\operatorname{erf}\left(\frac{x_{1}+x^{\prime}}{2 \sqrt{D_{1} t}}\right)\right] \\
& -\frac{1}{2} \sigma \int_{0}^{\infty} d x^{\prime} C_{0}\left(x^{\prime}\right) S\left(x^{\prime}, t\right) \\
& +\frac{D_{1} D_{2}}{D_{1}+D_{2}} \sum_{n=1}^{\infty} \sigma^{n-1}\left[I_{1 n}-I_{2 n}\right]
\end{aligned}
$$

where

$$
\begin{aligned}
S\left(x^{\prime}, t\right)= & \sum_{n=1}^{\infty} \sigma^{n-1}\left[\operatorname{erf}\left(\frac{(2 n+1)\left(x_{1}+x^{\prime}\right)}{2 \sqrt{D_{1} t}}\right)\right. \\
& +\operatorname{erf}\left(\frac{(2 n-1) x_{1}+x^{\prime}}{2 \sqrt{D_{1} t}}\right)-\operatorname{erf}\left(\frac{(2 n+1) x_{1}-x^{\prime}}{2 \sqrt{D_{1} t}}\right) \\
& \left.-\operatorname{erf}\left(\frac{(2 n-1) x_{1}-x^{\prime}}{2 \sqrt{D_{1} t}}\right)\right]
\end{aligned}
$$




$$
\begin{aligned}
I_{1 n} & =\int_{0}^{\infty} C_{0}\left(x^{\prime}\right) \operatorname{erfc}\left(\frac{2 n x_{1}+x^{\prime}}{2 \sqrt{D_{1} t}}\right) d x^{\prime} \\
I_{2 n} & =\int_{0}^{\infty} C_{0}\left(x^{\prime}\right) \operatorname{erfc}\left(\frac{2 n x_{1}-x^{\prime}}{2 \sqrt{D_{1} t}}\right) d x^{\prime} \\
\sigma & =\frac{\sqrt{D_{1} D_{2}}-D_{1}}{\sqrt{D_{1} D_{2}}+D_{1}}
\end{aligned}
$$

The release fraction is given by

$$
F(t)=1-\frac{c^{i n t}(t)}{\int_{0}^{\infty} c_{0}(x) d x}
$$

\subsubsection{Two Region Slab Without Trapping By Eigenfunction Expansion}

This approach was used by Austin and Elleman in Reference 10. In this approach, one takes advantage of the fact that

$$
\sin (\lambda x) e^{-\lambda^{2} D t}
$$

is a solution to the time dependent diffusion equation (without trapping). The concentration profiles are expanded in terms of these functions. After applying the boundary conditions, Austin and Elleman solved this problem for a particular $C_{0}(x)$. Generalizing their result, we have

$$
\begin{aligned}
& c_{1}=c_{0} \sum_{n=1}^{\infty} A_{n} \sin \left(\beta_{1 n} \frac{x}{x_{1}}\right) \exp \left(\frac{D_{1} \beta_{1 n} t}{x_{1}{ }^{2}}\right) \\
& c_{2}=c_{0} \sum_{n=1}^{\infty} A_{n}\left(\frac{\cos \beta_{1 n}}{\sqrt{\alpha} \cos \delta \beta_{1 n}}\right) \sin \left[\beta_{2 n}\left(\frac{x-x_{2}}{x_{1}}\right) \exp \left(\frac{-D_{1} \beta_{1 n}^{2}}{x_{1}{ }^{2}}\right)\right]
\end{aligned}
$$


where

$$
A_{n}=\frac{I_{1}+I_{2}}{I_{3}+I_{4}}
$$

where

$$
\begin{aligned}
& I_{1}=\frac{1}{x_{1}} \int_{0}^{x} c_{0}(x) \sin \left(\beta_{1 n} \frac{x}{x_{1}}\right) d x \\
& I_{2}=\frac{1}{X_{1}} \int_{X_{1}}^{X_{2}} C_{0}(x) \frac{\cos \beta_{1 n}}{\sqrt{\alpha} \cos \delta \beta_{1 n}} \sin \left[\beta_{1 n}\left(\frac{x-x_{2}}{x_{1}}\right)\right] d x \\
& I_{3}=\beta_{1 n}-\frac{\sin \left(2 \beta_{1 n}\right)}{2} \frac{\beta_{1 n}}{2} \\
& I_{4}=\left[\frac{\cos ^{2} \beta_{1 n}}{2 \sqrt{\alpha}{ }^{\beta_{1 n}} \cos ^{2} \delta \beta_{1 n}}\right]\left[\delta \beta_{1 n}-\frac{1}{2} \sin \left(2 \delta \beta_{1 n}\right)\right]
\end{aligned}
$$

and

$$
\begin{aligned}
& \alpha=\frac{\mathrm{D}_{2}}{\mathrm{D}_{1}} \\
& \delta=\frac{1}{\sqrt{\alpha}} \frac{\mathrm{x}_{2}}{\mathrm{x}_{1}}-1
\end{aligned}
$$


The release fraction is given by

$$
\begin{aligned}
F(t)= & 1-\frac{1}{c_{0}^{\text {int }}} \sum_{n} \frac{A_{n}}{\beta_{1 n}} \mid\left(1-\cos \beta_{1 n}\right) \\
& \left.+\frac{\cos \beta_{1 n}}{\cos \delta \beta_{1 n}}\left(\cos \left[\frac{\beta_{1 n}}{\sqrt{\alpha}}\left(\frac{x_{1}-x_{2}}{x_{1}}\right)\right]-1\right) \exp \left(\frac{-D_{1} \beta_{1 n}^{2}}{x_{1}^{2}} t\right)\right\}
\end{aligned}
$$

where

$$
c_{0}^{\text {int }}=\int_{0}^{x_{2}} c_{0}(x) d x
$$

It becomes much more difficult to apply this technique, or the Green's function approach to a problem involving reversible trapping.

\subsubsection{Composite Solid with Reversible Trapping}

To solve the general problem of a composite solid with reversible trapping, we must utilize numerical techniques. The author has worked with Oster ${ }^{(19)}$ to develop a computer code for solving this problem. Difference techniques have been utilized. The code will determine concentration profiles versus time and gas release fraction versus time. The composite solid may consist of more than two regions. Let us briefly consider the numerical approach utilized and then examine some calculated results.

Let $x_{r j}$ denote the right hand end point $j$, and take $x_{r o}=0$. Thus, if we have $J$ regions, we have

$$
0=x_{r_{0}}<x_{r j}<-\cdots<x_{r j}
$$


We now consider the problem of solving for $C_{j}(x), m_{j}(x)$ and $M_{j}(x)$, $j=1,2,---J$, where the functions are solutions to

$$
\begin{aligned}
& \frac{\partial C}{\partial t}=D_{j} \frac{\partial^{2} C}{\partial x}-\frac{\partial m}{\partial t}-\frac{\partial M}{\partial t} \\
& \frac{\partial m}{\partial t}=k_{j} C-k^{\prime} \\
& \frac{\partial M}{\partial t}=k_{j} C
\end{aligned}
$$

with the boundary conditions

$$
\begin{aligned}
& C(x, 0)=c^{(0)}(x) \\
& M(x, 0)=M^{(0)}(x) \\
& m(x, 0)=m^{(0)}(x) \\
& c(x=0, t)=0 \\
& c\left(x_{r j}, t\right)=0 \\
& \lim c(x, t)=\lim c(x, t) \\
& x \rightarrow x_{r j}-x \rightarrow x_{r j}+ \\
& \lim \left(D_{j} \frac{\partial C}{\partial x}\right)=\lim \left(D_{j+1} \frac{\partial C}{\partial x}\right) \\
& x \rightarrow x_{r j} \quad x \rightarrow x_{r j}+
\end{aligned}
$$

where $x \rightarrow x_{r j}$ - indicates $x$ approaches $x_{r j}$ from the left and $x \rightarrow x_{r j+}$ indicates the approach is from the right. 
Using difference techniques, a computer program has been developed in FORTRAN IV. ${ }^{19}$ The code will accept up to 10 regions with a total of 200 points $x_{j}$. Results of calculations are discussed in the next section.

\subsection{COMPUTER CODE FOR GAS RELEASE CALCULATIONS}

There have been no previous calculations concerning a composite solid with reversible trapping. As a result, to check out the computer program, special cases of the general problem were examined. In particular, calculations were carried out for a composite solid with no trapping and for a slab with reversible trapping.

Austin, et al., studied the composite solid with no trapping, and with the initial concentration profile given by

$$
C_{0}(X)=C_{0}\left(1-\frac{x}{R}\right)
$$

where $\mathrm{R}$ refers the alpha particle range. We have carried out calculations for this problem with the computer code referred to above. Results have been obtained which agree with Austin, et al. The gas release fraction is plotted versus a dimensionless time parameter $\tau=D_{1} t / x_{1}{ }^{2}$ in Figure 6 as was done by Austin, et al. Results are shown for $x_{1}=5 \times 10^{-4} \mathrm{~cm}$, $R=20 \times 10^{-4} \mathrm{~cm}$ and $X_{2}=0.635 \mathrm{~cm}$. The curve for $D_{2} / D_{1}=1$ corresponds to a homogeneous solid. Results for $\mathrm{D}_{2} / \mathrm{D}_{1}=10^{4}$ correspond to a situation where diffusion in the surface region is much slower than in the bulk region. The release fraction versus time is identical for the two cases until $\tau \approx 0.2$. After this point in time, diffusion of atoms to the bulk is much faster than to the front surface, and therefore, $F(t)$ is reduced.

The same results are shown in Figure 7 . In this case, however, $F(t)$ is plotted versus $t^{1 / 2}$, the square root of real time. Again, the reduction in release fraction in the case of $D_{2} / D_{1}=10^{4}$ occurs after adequate time passes for gas atoms to begin diffusing significantly into the bulk region. Note that $F(t) \sim t^{1 / 2}$ for $t \lesssim 25 \times 10^{4}$ seconds, or for the first 


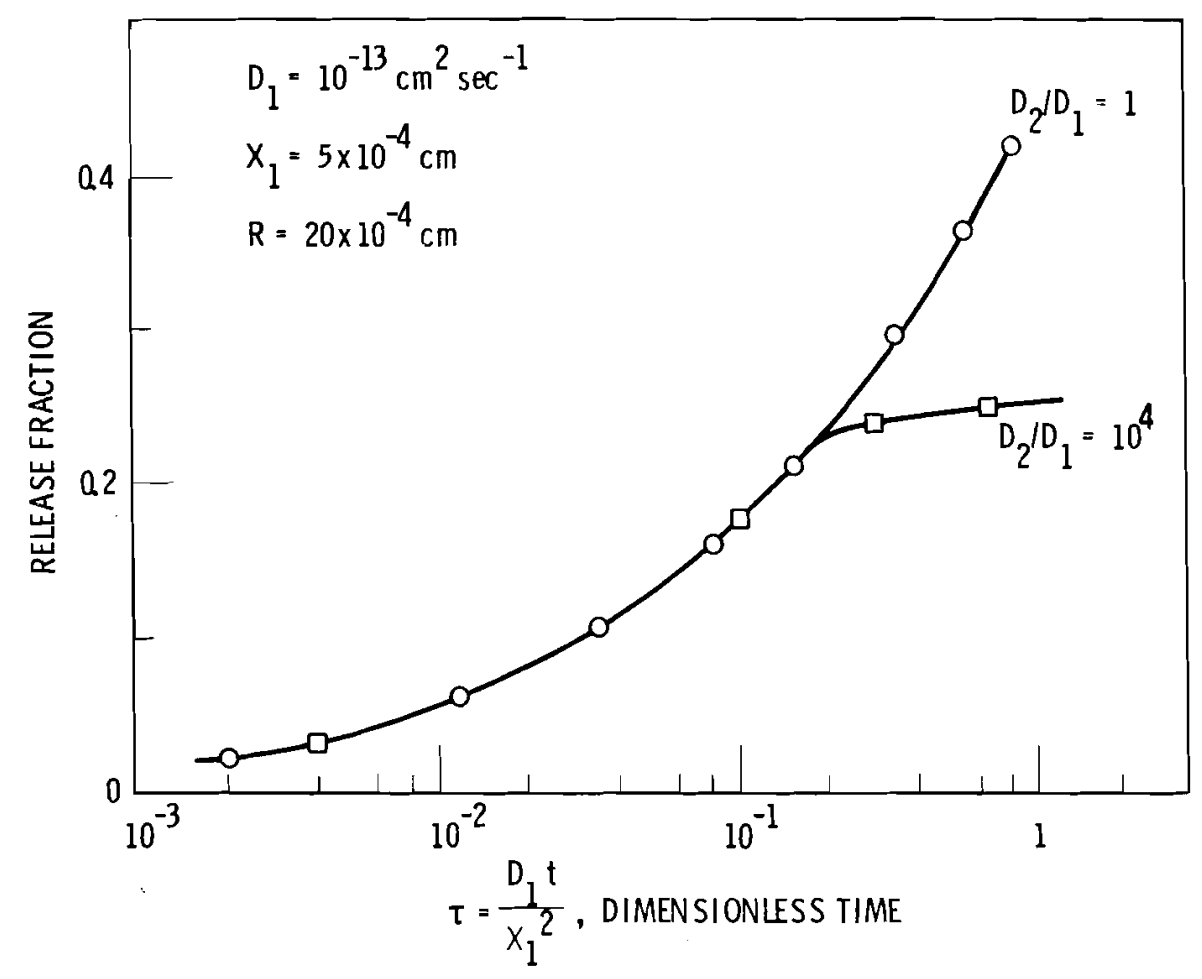

FIGURE 6. Re1ease Fraction for Two-Region Composite Solid without Trapping versus Dimensionless Time

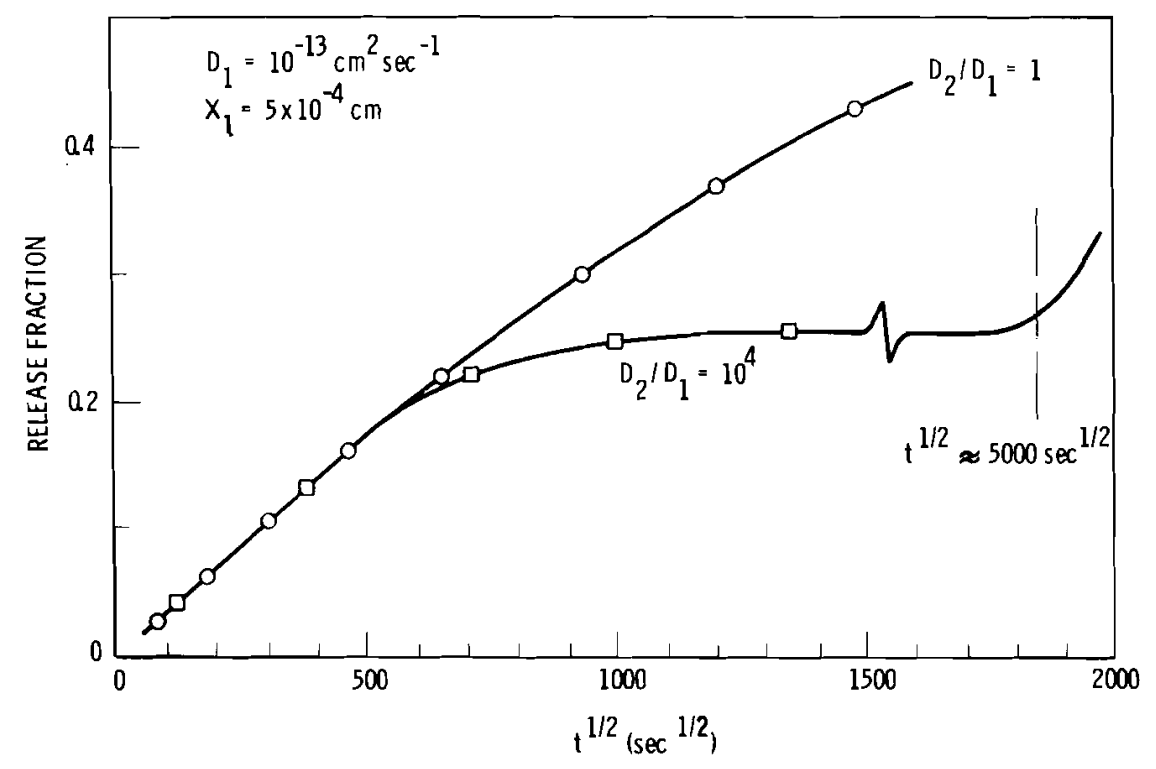

FIGURE 7. Re1ease Fraction for Two-Region Composite Solid without Trapping versus Square-Root of Time 
69 hours. $F(t)$ behaves this way for a rather long time period because $D_{1}$ is so sma11. It is interesting to note that $D$ for the surface region can be obtained from the initial behavior of $F(t)$.

Figure 8 illustrates the behavior of $C(X, t)$ for various values of time. The triangular, initial concentration is shown. The concentration profile is given for $t=2.5 \times 10^{5}$ and $t=5.0 \times 10^{5} \mathrm{sec}$. It is important to note that the region boundary is at $x_{1}$, and that the initial concentration profile extends beyond $x_{1}$. In the homogeneous case, gas atoms diffuse into the bulk as easily as they diffuse to the surface. In the case $\mathrm{D}_{2} / \mathrm{D}_{1}=10^{4}$, gas atoms diffuse rapidly into the bulk, thereby reducing the surface concentration much more rapidly than in the homogeneous case.

Calculations were carried out for another special case, namely, for a homogeneous slab with reversible trapping. Identical values were chosen for $k$ and $k^{\prime}$, as were selected by Ong and El leman in Reference 5. In particular, we obtain very good agreement with their results for $k=10^{-3} \mathrm{sec}^{-1}$ and $k^{\prime}=10^{-4} \mathrm{sec}$.

No one has carried out studies for a composite solid with reversible trapping. As a result, the code can only be tested for cases involving the composite solid and no trapping, or a single region system with reversal trapping. Future studies will involve two-region systems with reversible trapping. 


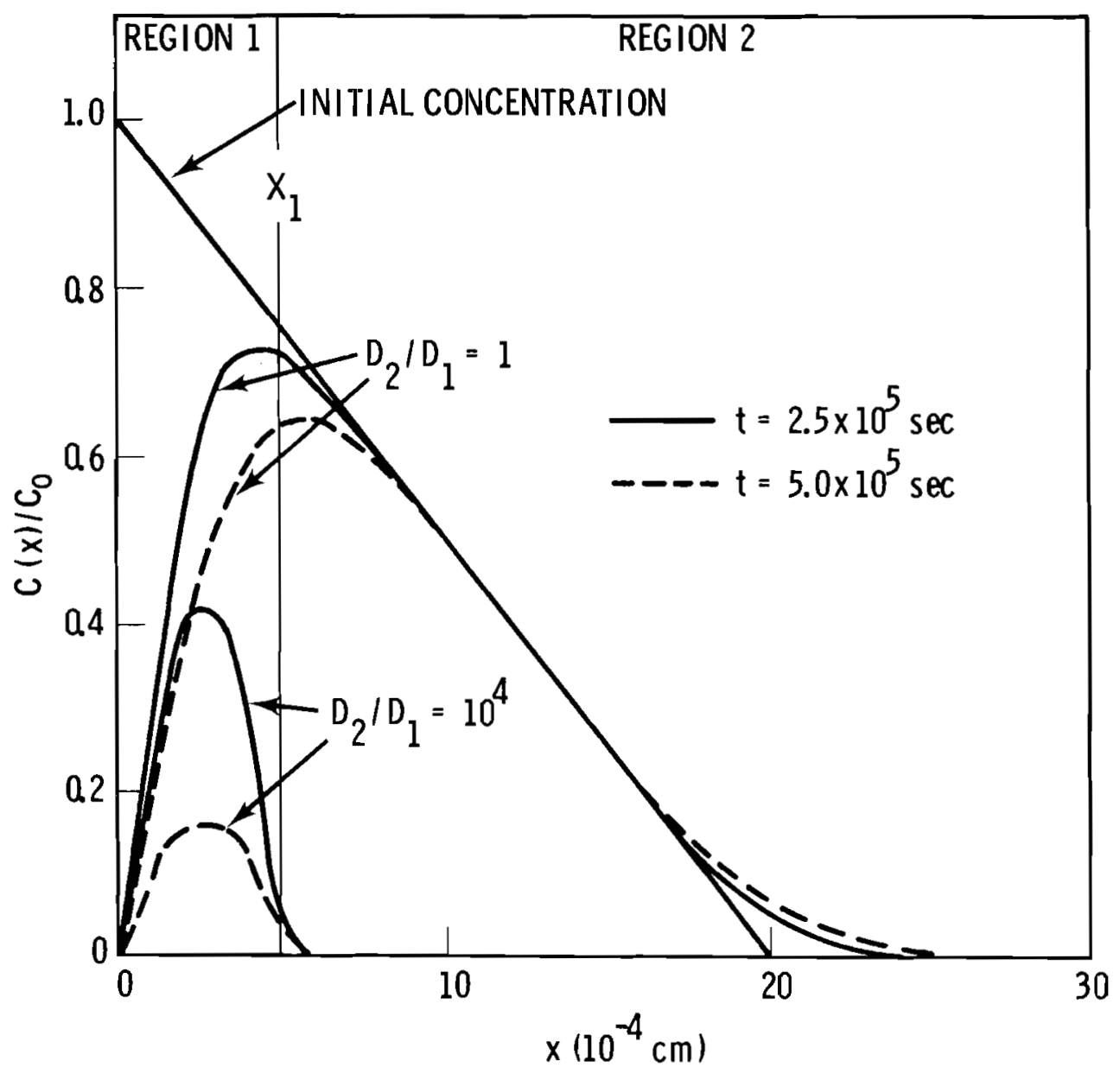

FIGURE 8. Concentration Profile for Two-region Composite Solid without Trapping for $D_{1}=10^{-13} \mathrm{~cm}^{2} \mathrm{sec}^{-}$ and $D_{2} / D_{1}=1$ and $10^{4}$ 


\subsection{INITIAL CONCENTRATION PROFILE}

Studies of gas release phenomena involve three main tasks, determination of the initial concentration profile $C_{0}(x)$, formulation of analysis for gas diffusion and release sample geometries of interest, and determination of experimental approach to measurement of gas release. In this section, we will examine the problem of determining $C_{0}(x)$.

The initial concentration profile must be known before release data can be utilized to determine diffusion parameters. If thin foils of the sample material are available, then $C_{0}(x)$ can be obtained directly by irradiating a stack of foils, melting each foil to determine the total helium content, and then correlating the amount of helium with the distance traveled by the alpha particles.

$c_{0}(x)$ can also be calculated if the alpha source is sufficiently characterized. In the following sections, the initial concentration profile expected for a monoenergetic, infinitesimally thin source and a semi-infinite alpha particle source are considered.

\subsection{MONOENERGETIC SOURCE}

Consider a semi-infinite sample coupled to a planar alpha-particle source of infinitesimal thickness. Assume that $N_{0} \alpha^{\prime} s$ are emitted per unit area to one side. Let $c(x)$ be the number of $\alpha^{\prime} s$ absorbed per $\mathrm{cm}^{3}$ in a semi-infinite solid. Referring to Fiqure 9 ,

$$
\begin{aligned}
C(x) & =\left[\begin{array}{l}
\text { Total \# } \alpha^{\prime} s \\
\text { Absorbed per } \mathrm{cm}^{3} \\
\text { at depth } x
\end{array}\right] \\
& =\frac{1}{\Delta x\left(1 \mathrm{~cm}^{2}\right)}\left(\frac{1 \mathrm{~cm}^{2}}{\Delta A}\right)\left(N_{0} \Delta x\right) \frac{R_{0} \Delta \theta 2 \pi R_{0} \sin \Theta_{0}}{2 \pi R^{2}} . \\
& =N_{0} \frac{\sin \Theta}{d x} d \theta
\end{aligned}
$$


liow,

$$
\begin{aligned}
& \frac{x}{R_{0}}=\cos \theta \\
& |d x|=R_{0} \sin \theta_{0} d \theta
\end{aligned}
$$

Therefore,

$$
\begin{aligned}
& C(x)=\frac{N_{0}}{R_{0}} \quad x \leq R_{0} \\
& 0 \quad x>R_{0}
\end{aligned}
$$

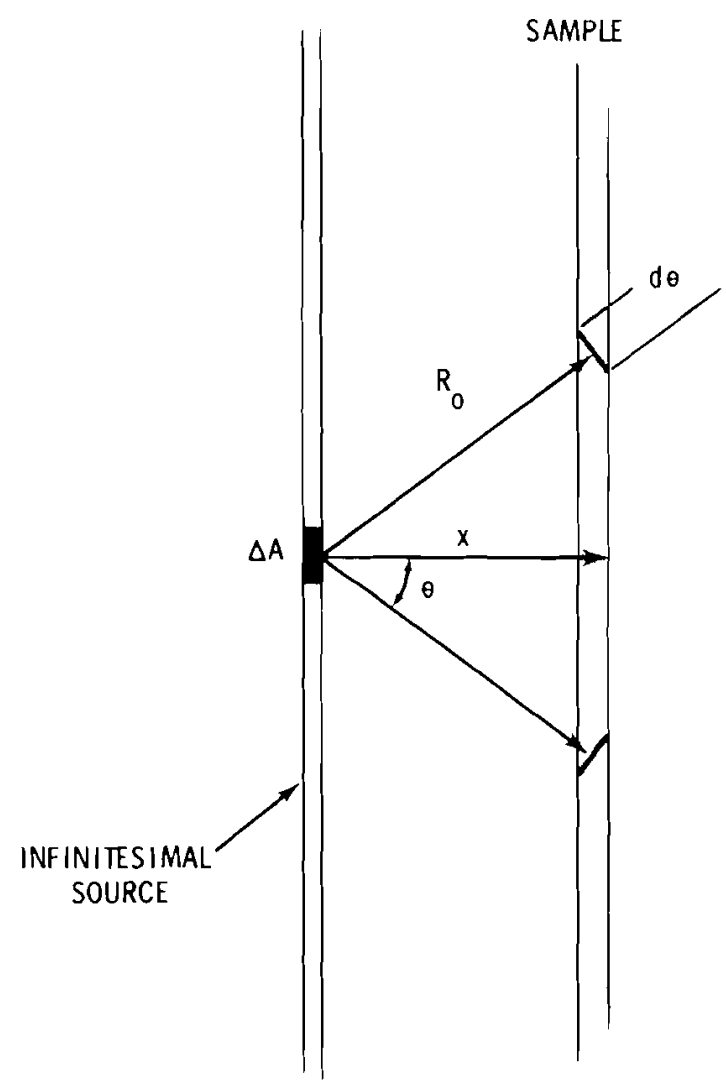

FIGURE 9. Geometry for Infinitesimally Thin Source Coupled to Semi-Infinite Sample. 
The concentration profile is a constant for $x \leq R_{0}$, and zero for larger $x$. This profile is often referred to as a rectangular concentration profile.

This profile is appropriate for either a thin film source utilizing an alpha-emitting isotope, or a thin film layer utilized with fission recoil to produce a flux of alpha particles.

\subsection{SEMI-INFINITE SOURCE}

The concentration profile in a sample resulting from being coupled to a semi-infinite source is particularly important. The profile has been derived by several people by assuming $E$ decreases 1 inearly with distance. This approach results in the triangular profile used by Elleman, $C(x)=C_{0}(1-x / R)$. In the approach discussed below, we assume that the alpha particle spectrum, $N(E)$, which emerges from the source, and the rangeenergy relationship, $R(E)$, are known. $C(x)$ is calculated for an alpha source coupled to aluminum. The results can be significantly different from a triangular profile, depending on the choice for $N(E)$.

Consider a semi-infinite solid containing $\alpha$ - emitting atoms dispersed homogeneously throughout the material. Let $\Delta N_{x}$ be the number of alphas passing through an area $\triangle A$ on the surface which originate from a hemispherical she 11 of radius $x$ (see $F$ igure 10 ). The number of alphas passing through $\triangle A$ is given by

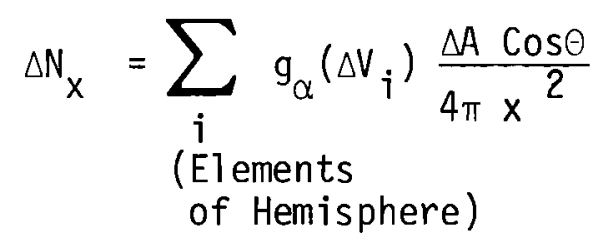

where

$$
\begin{aligned}
& g_{\alpha}=\left[\begin{array}{l}
\text { Number } \alpha^{\prime} s \\
\text { emitted per } \\
\text { unit volume } \\
\text { per second. }
\end{array}\right] \\
& \Delta v_{\mathbf{i}}=x^{2} \sin \theta \text { d } \theta d \phi d x
\end{aligned}
$$




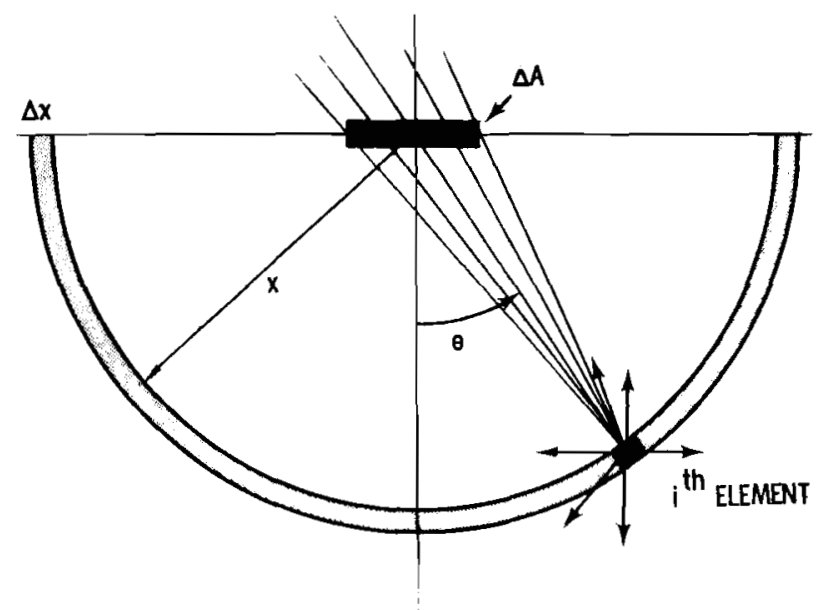

FIGURE 10. Geometry for Semi-Infinite Alpha-Particle Source.

Writing the sum in integral form,

$$
\Delta N_{x}=\frac{g_{\alpha} \Delta A \Delta x}{4} \int_{0}^{2 \pi} d \phi \int_{0}^{\pi / 2} d \theta \sin \theta \cos \theta
$$

or

$$
\Delta N_{x}=\frac{g_{\alpha} \Delta A \Delta x}{4}
$$

The flux of alpha particles is

$$
\Delta \phi_{X}=\frac{\Delta N_{X}}{\Delta A}=\frac{g_{\alpha}}{4} \Delta x
$$

$\Delta x$ can be expressed in terms of $E$. Such an expression gives the loss of energy $\Delta \mathrm{E}$ suffered by the particle while moving $\Delta \mathrm{x}$, and which has an energy $E$. To derive the flux of alphas and their energy spectrum, we must specify the relationship between $x$ and $E$. 
Before considering the effects of specifying $R(E)$, it is worthwhile to derive a result for the total flux emitted from a semi-infinite source. Let $\Phi$ be the total flux of alpha particles emitted per $\mathrm{cm}^{2}$.

$$
\Phi=\left(\begin{array}{c}
N_{0} \alpha^{\prime} s \\
\text { emitted } \\
\text { per cm2 }
\end{array}\right)=\int_{0}^{R} \frac{g_{\alpha}}{4} d x
$$

or

$$
\Phi=\frac{g_{\alpha} R}{4}
$$

Consider a layer of thickness, R. The total number of $\alpha^{\prime}$ s emitted per $\mathrm{cm}^{2}$ of surface area is $g_{\alpha} R \alpha^{\prime} s / \mathrm{cm}^{2}$. The fraction of $\alpha^{\prime} s$ which are emitted from the surface is

$$
\begin{aligned}
& \text { Fraction } \\
& \text { Emitted }
\end{aligned}=\frac{g_{\alpha} R / 4}{g_{\alpha} R}=1 / 4
$$

Let us now consider a specific case where the range-energy relationship is given by the Geiger relationship, namely,

$$
d x=\frac{3 R}{2} \frac{E_{x}^{1 / 2}}{E_{0}^{3 / 2}} d E_{x}
$$

Substituting this in (84)

$$
\begin{aligned}
\Delta \phi_{x} & =\left(\frac{3 R_{\alpha}}{8} \frac{E_{x}^{1 / 2}}{E_{0}^{3 / 2}}\right) \Delta E_{x} \\
& =N(E) \Delta E
\end{aligned}
$$


Thus, if the Geiger relationship is valid, the alpha particle energy spectrum is given by

$$
N(E)=\left(\frac{3 R g_{\alpha}}{8 E_{0}^{3 / 2}}\right) E^{1 / 2}
$$

\subsection{CONCENTRATION PROF ILE FOR ARBITRARY N(E)}

Consider an isotropic flux of alphas incident onto a semi-infinite sample. Suppose the energy spectrum $N(E)$ is known. Referring to Figure 9, we consider the number of alphas absorbed in an infinitesimal slab of thickness $\Delta x$ at $x$ due to alphas emitted from $\Delta A$ we have

$$
\begin{aligned}
{[N(x)]_{\Delta A} } & =\left[\begin{array}{l}
\text { a's absorbed in an } \\
\text { infinitesimal slab } \\
\Delta x \text { at } x \text { due to a's } \\
\text { emitted from } \Delta A
\end{array}\right] \\
& =\sum_{i=i_{x}}^{i_{0}}\left(N\left(E_{i}\right) \Delta E \Delta A \frac{R_{i} \Delta \Theta\left(2 \pi R_{i} \sin \Theta_{i}\right)}{2 \pi R_{i}{ }^{2}}\right. \\
& =\sum_{i=i_{x}}^{i_{0}} N\left(E_{i}\right) \Delta E \Delta A \sin \Theta_{i} \Delta \theta
\end{aligned}
$$

where

$$
R_{i_{x}}=x \text { and } \quad R_{i_{0}}=R_{0}
$$

Now to account for all of the alpha source, we must multiply $[N(x)]_{\triangle A}$ by $A / \Delta A$. Thus,

$$
N(x)=\frac{A}{\Delta A}[N(x)]_{\Delta A}
$$


To obtain $C(x)$, we divide by $A(\Delta x)$,

$$
C(x)=\frac{N(x)}{A(\Delta x)}
$$

We now have

$$
\begin{aligned}
& C(x)=\sum_{i_{x}}^{i_{0}} N\left(E_{i}\right) \Delta E \frac{\sin \theta_{j} \Delta \theta}{\Delta x} \\
& C(x)=\sum_{i_{x}}^{i_{0}} \frac{N\left(E_{i}\right) \Delta E}{R_{j}\left(E_{i}\right)}
\end{aligned}
$$

where we have set

$$
\Delta x=\left(R_{i} \Delta \theta\right) \sin \Theta_{i}
$$

Letting $\Delta E \rightarrow 0$, we obtain

$$
C(x)=\int_{E_{X}}^{E^{0}} \frac{N(E) d E}{R(E)}
$$

or

$$
C(x)=\int_{x}^{R_{0}} \frac{N(E)}{R(E)} \quad \frac{d E}{d R} \quad(d R)
$$


We can calculate $C(x)$ for a given alpha source and material if $N(E)$ and $R(E)$ are known. If the Geiger relationship is assumed, then $N(E) \propto E^{1 / 2}$. Matzke, ${ }^{22}$ however, has measured a linear relationship. It is also common to calculate $R(E)$ by utilizing the known range of alpha particles in air and assuming that $R_{p} / \sqrt{A}$ is constant for different materials. Figure 11 shows calculated results using numerical estimates for $C(x)$ assuming: (a.) $R$ is proportional to $E$ (indicated by $R \propto E$ ) and $N(E)$ is proportional to $E$; (b.) $R(E) \propto R_{a}$ ir $(E)$ and $N(E) \propto E$; (c.) $R(E) \propto R_{\text {air }}(E)$ and $N(E) \propto E^{1 / 2}$.

It can be seen from equations $(84,95)$ that a linear relation for $C(E)$ vs $x$ results only if $R(E)$ and $N(E)$ both have the same energy dependence $[1 . e . R(E) \propto N(E)]$. The other approaches give nonlinear plots for $c(x)$.

Experimental studies of the initial concentration therefore need to be undertaken. Many gas release analyses have been done assuming $C(x)=C_{0}\left(1-\frac{x}{R}\right)$. If the initial concentration is linear, then the Geiger relationship and $R(E) \times R_{a i r}$ assumptions are wrong.

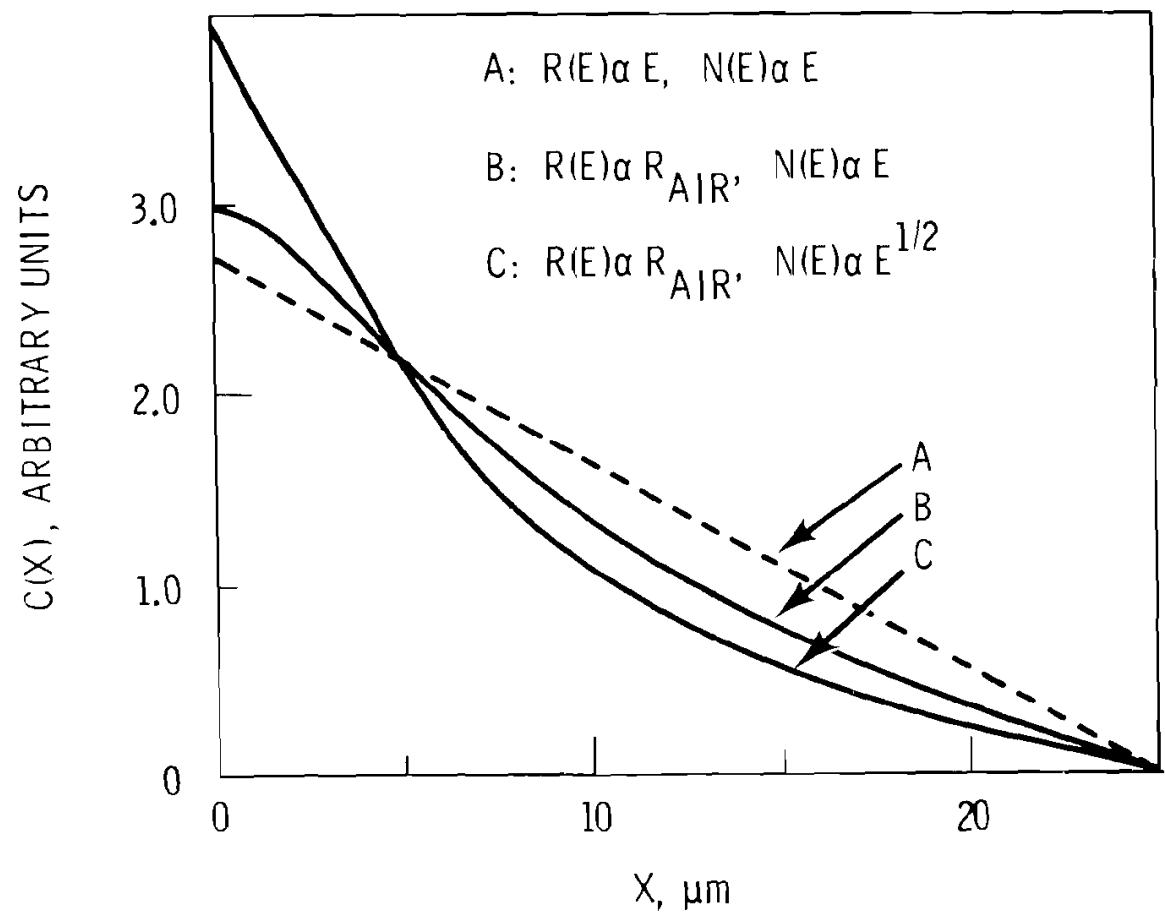

FIGURE 11. Calculated Helium Concentration Profile for Aluminum Coupled to Semi-Infinite Alpha Source with $N(E) \sim \sqrt{E}$ and $E_{\max }=5.5 \mathrm{MeV}$. Experimental results were used for $R(E)$. 


\subsection{SUMMARY}

Experimental and theoretical aspects of inert gas diffusion and release from solids have been discussed. An overview of previous gas release studies has been given. Particular emphasis was placed on work done by Elleman, Kelly and Matze. Theoretical approaches to the diffusion and gas release problem were examined. In particular, gas release from single region and composite solids was studied with and without trapping. Results obtained with a computer code developed for a composite solid with reversible traping were discussed. Finally, approaches to calculating the initial concentration profile in samples which have been irradiated with alpha particles were considered. 


\subsection{REFERENCES}

1. D. L. Douglass and S. E. Bronisz, "Alpha Particle Irradiation Damage in $\mathrm{ThO}_{2}$," Jour. Amer. Ceramic Soc. 54, 158(1971).

2. D. L. Morrison, T. S. Elleman and D. N. Sunderman, "Diffusion of Xenon in Ceramic 0xides," Jour. Appl. Physics 35, 1616(1964).

3. T. S. Elleman, L. D. Mears and R. P. Christman, "Rare Gas Diffusion in Cesium Iodide: Use of Fission Recoil Doping Techniques," Jour. Amer. Ceramic Soc. 51, 560(1968).

4. T. S. Elleman, C. H. Fox and L. D. Mears, "Influence of Defects on Rare-Gas Diffusion in Solids," Jour. Nucl. Matls. 30, 89(1969).

5. A. S. Ong and T. S. Elleman, "Effect of Trapping on the Release of Recoil Injected Gases from Solids," Nucl. Instruments and Methods 86, $117(1970)$.

6. T. S. Elleman and A. S. Ong, "Surface Effects on the Diffusion Release Rate of Rare Gases," Phys. Stat. Sol. 3, 921(1970).

7. L. D. Mears and T. S. Elleman, "Rare Gas Diffusion in Alkali Metal Iodides," Phys. Stat. Sol. 7, 509(1971).

8. A. S. Ong and T. S. Elleman, "Diffusion and Trapping of Rare Gas Xenon in Calcium Fluoride Single Crystals," Jour. Nucl. Matls. 42, 191(1972).

9. J. C. Carter, E. J. Driscoll and T. S. El leman, "Xenon-133 Diffusion and Trapping in Single-Crystal Uranium Dioxide," Phys. Stat. Sol. 14, 673(1972).

10. J. H. Austin, T. S. Elleman and K. Verghese, "Surface Effects on the Diffusion of Tritium in 304-Stainless Steel and Zircaloy-2," Jour. Nucl. Mat1s. 48, 307(1973).

11. Roger Kelly and H. Matzke, "The Application of Diffusion Theory to Inert-Gas Motion in Ion-Bombarded Solids," Jour. Nucl. Matls. 20, $171(1966)$.

12. G. Dicola and H. Matzke, "The Determination of Rare Gas Diffusion following Recoil Labelling of Plane or Spherical Solids," Nuclear Instruments and Methods 57, 341 (1967).

13. R. Kelly and C. Jech, "On the Mechanisms of Diffusion in Inert-Gas Bornbarded Solids. Diffusion Theory for Discrete Media, Part V," Jour. Nucl. Matls. 30, $122(1969)$. 
14. R. Kelly and L. Q. Nghi, "Diffusion in Ion-Implanted Solids with Non-Uniform Diffusion Parameters," Radiation Effects 6 6, 247 (1970).

15. D. G. Hurst, "Diffusion of Fission Gas," CRRP-1124 (Atomic Energy of Canada, Ltd., Chalk River, Ont., Nov. 1962).

16. H. Gaus, Z. Naturforsch 20a, 1298 (1965).

17. W. Inthoff and K. E. Zimen, "Kinetics of Diffusion of Radioactive Rare Gases from Solid Substances after Irradiation, " AEC-tr-3289, no. 176 (Trans. Chalmers Univ. Technol., Gothenburg, 1956).

18. A. H. Booth and G. Rymer, "Determination of the Diffusion Constant of Fission Xenon in $\mathrm{UO}_{2}$ Crystals and Sinter Compacts," AECL Chalk River Report CRDC-720 (1958).

19. C. A. Oster, BNWL 1987, "DIGRTS-A Computer Code for Studying the Diffusion of an Inert Gas in Composite Solids with Reversible Trapping," Feb. (1976).

20. "Nuclear Radiation Detection," By W. J. Price, McGraw-Hill Book Co. (1964).

21. "Conduction of Heat in Solids," by H. S. Carslaw and J. C. Jaeger, Oxford University Press (1959).

22. H. J. Hirsch and $\mathrm{H}_{j}$. Matzki, "Stopping Power and Range of $\alpha$-Particles in (U, Pu)C and UC and Application to Self-Diffusion Measurements Using Alpha-Spectroscopy. J. Nuc. Mat. 45, 29 (1972/73). 


\section{APPENDIX I}

\section{GREEN'S FUNCTION FORMULATION FOR SEMI-INFINITE SOLID}

We are interested in diffusion of an inert gas in a semi-infinite solid, with and without trapping, and for two sets of boundary conditions. We define a Green's function $g\left(x, x^{\prime} ; t\right)$ which is a solution to the one-dimensional diffusion problem when the initial gas concentration is a spike of unit strength at $x=x^{\prime}$ and time zero. Note that a "spike" is essentially a plane source in the semi-infinite solid. The term unit strength is understood to mean

$$
\int_{0}^{\infty} g\left(x, x^{\prime} ; t\right) d x^{\prime}=1
$$

As discussed in Chapter 14 of Carslaw and Jaeger, ${ }^{21}$ one can show that the concentration of gas at time $t$ and at position $x, c(x, t)$ for the case of an initial concentration $C_{0}(x)$, is given by

$$
C(x, t)=\int_{0}^{\infty} g\left(x, x^{\prime} ; t\right) C_{0}\left(x^{\prime}\right) d x^{\prime}
$$

The Green's function is essentially a transfer function. It indicates the magnitude of the concentration at $(x, t)$ when the gas started as a spike at $x^{\prime}$ and $t=0$. The interesting and valuable feature about the Green's function approach is that $g\left(x, x^{\prime} ; t\right)$ only has to be solved one time for each geometry. Normally, rather sophisticated techniques are required to determine $g\left(x, x^{\prime} ; t\right)$. Typically, the method of Laplace transforms is utilized. There are two Green's functions of interest for problems with the semiinfinite solid, namely, for one for a surface boundary condition of $c(x=0, t)=0$, and the other involving the flux being proportional to the concentration at the surface. Expressions for $g\left(x, x^{\prime} ; t\right)$ and appropriate boundary conditions are: 
(a) Zero Surface Concentration;

$$
\begin{aligned}
& g\left(x=0, x^{\prime} ; t\right)=0 \\
& \lim _{x \rightarrow \infty} g\left(x, x^{\prime} ; t\right)=0 \\
& g\left(x, x^{\prime} ; t\right)=\frac{1}{2 \sqrt{\pi D t}}\left\{\exp \left[\frac{\left(x-x^{\prime}\right)^{2}}{4 D t}\right]+\exp \left[\frac{\left(x+x^{\prime}\right)^{2}}{4 D t}\right]\right\}(A-3)
\end{aligned}
$$

(b) Surface Transfer Coefficient

$$
\begin{aligned}
D\left(\frac{\partial g}{\partial x}\right)_{x=0} & =H g\left(x=0, x^{\prime} ; t\right) \\
\lim _{x \rightarrow \infty} g\left(x, x^{\prime} ; t\right) & =0 \\
g\left(x, x^{\prime} ; t\right) & =\left[g\left(x, x^{\prime} ; t\right)\right]_{\text {zero surface concentration }} \\
& -h \exp \left[D t h^{2}+h\left(x+x^{\prime}\right)\right] \operatorname{erfc}\left[\frac{x+x^{\prime}}{2 \sqrt{D t}}+h \sqrt{D t}\right]
\end{aligned}
$$

where $h=H / D$

Utilizing (A-2) with the proper Green's function and $C_{0}(x)$, one can solve the problem. It should be emphasized that the functions $q\left(x, x^{\prime} ; t\right)$ are the so-called plane source solutions referred to by Kelly. Solving a problem with Green's functions clearly amounts to integrating the effects of gas atoms diffusing through the solid from plane sources arranged according to $C_{0}(x)$. 


\section{APPENDIX II}

\section{COMPOSITE SEMI-INFINITE SOLID}

Consider a composite solid with diffusion parameters as indicated in Figure 5. We assume the following boundary conditions

$$
\begin{aligned}
& C_{1}(0, t)=0 \\
& \lim _{x \rightarrow \infty} C_{2}(x, t)=0 \\
& C_{1}\left(x=x_{1}, t\right)=C_{2}\left(x=x_{1}, t\right) \\
& D_{1}\left(\frac{\partial C_{1}}{\partial x}\right)_{x=x_{1}}=D_{2}\left(\frac{\partial C_{2}}{\partial x}\right)_{x=x_{1}}
\end{aligned}
$$

Our goal is to determine $C(x, t)$ in the case of $C_{0}(x)$ being known so that $c^{i n t}(t)$ can be calculated. We will determine a Green's function for a unit plane source at $x=x^{\prime}$ where $0 \leq x^{\prime} \leq x_{1}$. In other words, we are only interested in problems where $C_{0}(x)=0$ for $x>x_{1}$.

We will write

$$
g\left(x, x^{\prime} ; t\right)= \begin{cases}g_{1}\left(x, x^{\prime} ; t\right) & 0 \leq x \leq a \\ g_{2}\left(x, x^{\prime} ; t\right) & x \geq a\end{cases}
$$

The Green's function is used in the following manner:

$$
\begin{aligned}
& c(x, t)=\int_{0}^{\infty} c_{0}\left(x^{\prime}\right) g\left(x, x^{\prime} ; t\right) d x^{\prime} \\
& =\sum_{n} \int_{0}^{\infty} C_{0}\left(x^{\prime}\right) g_{n}\left(x, x^{\prime} ; t\right) d x^{\prime} \quad n=\left\{\begin{array}{cc}
1 & 0 \leq x \leq x_{1} \\
2 & x \geq x_{1}
\end{array}\right.
\end{aligned}
$$


We assume $g_{1}$ is given by the Green's function for a semi-infinite medium, that is $(A-3)$, plus another term to be determined. Let

$$
g_{1}=w_{1}+u
$$

where

$$
u=\frac{1}{2 \sqrt{\pi D_{1}+}}\left\{\exp \left[-\frac{\left(x-x^{\prime}\right)^{2}}{4 D_{1} t}\right]-\exp \left[\frac{\left(x+x^{\prime}\right)^{2}}{4 D_{1} t}\right]\right\}
$$

Assuming zero surface concentration boundary conditions, $w_{1}$ and $g_{2}$ must satisfy

$$
\begin{aligned}
& \text { (a.) } \mathrm{w}_{1}=0, \mathrm{x}=0 \\
& \text { (b.) } \mathrm{g}_{1}=\mathrm{g}_{2}, \mathrm{x}=\mathrm{x}_{1} \\
& \text { (c.) } \mathrm{D}_{1}\left(\frac{\partial \mathrm{g}_{1}}{\partial \mathrm{x}}\right) \mathrm{x}=\mathrm{x}_{1}=\mathrm{D}_{2}\left(\frac{\partial \mathrm{g}_{2}}{\partial \mathrm{x}}\right) \mathrm{x}=\mathrm{x}_{1} \\
& \text { (a.) } \mathrm{g}_{2}=0 \text { as } \mathrm{x} \rightarrow \infty
\end{aligned}
$$

The diffusion equation is, of course,

$$
\frac{\partial C}{\partial t}=D \frac{\partial^{2} C}{\partial x^{2}}
$$

The functions $g_{1}, g_{2}, u$ and $w_{1}$ must also satisfy this equation. We take the Laplace transform to obtain a linear differential equation which is only a function of $x$. We have two unknowns, $w_{1}$ and $g_{2}$. The corresponding differential equations for the transforms are

$$
\begin{array}{ll}
\frac{d^{2} \bar{w}_{1}}{d x^{2}}-q_{1}^{2} \bar{w}_{1}=0 & q_{1}=\sqrt{\frac{\bar{D}_{1}}{d^{2} \bar{g}_{2}}} \\
\frac{d x^{2}}{d^{2}} q_{2}^{2} \bar{g}_{2}=0 & q_{2}=\sqrt{\frac{P}{D_{2}}}
\end{array}
$$


$\bar{f}$ is the Laplace transform of $f$ and is given by

$$
\bar{f}(p)=\int_{0}^{\infty} e^{-p t} f(t) d t
$$

We have

$$
\begin{aligned}
& \overline{\mathrm{w}}_{1}=A \sinh (q, x)+B \cosh (q, x) \\
& \bar{g}_{2}=C e^{-q_{2} x}+D e^{-q_{2} x}
\end{aligned}
$$

Applying boundary conditions (a) through (d) we obtain

$$
\begin{aligned}
& g_{1}=\bar{u}+\frac{q_{1} D_{1}-q_{2} D_{2}}{2 q_{1} D_{1}}\left[\frac{e^{-q_{1}\left(x_{1}-x^{\prime}\right)}-e^{-q_{1}\left(x_{1}+x^{\prime}\right)}}{\alpha_{1} \cosh \left(q x_{1}\right)+\alpha_{2} \sinh \left(q_{1} x_{1}\right)}\right] \sinh \left(q_{1} x\right) \\
& \bar{g}_{2}=\frac{1}{2}\left\{\frac{e^{-q_{1}\left(x_{1}-x^{\prime}\right)}-e^{-q_{1}\left(x_{1}+x^{\prime}\right)}}{q_{1} D_{1} \cosh \left(q_{1} x_{1}\right)+q_{2} D_{2} \sinh \left(q x_{1}\right)}\right\} e^{q_{2}\left(x_{1}-x\right)} \\
& a_{i}=q_{1} D_{i}
\end{aligned}
$$

The next, and final, step in determining $g(x, x ; t)$ involves taking the inverse transform of $\mathrm{g}$. There are tables available which expedite this process. In order to take the inverse of $\bar{g}_{1}$ and $\bar{g}_{2}$, it is necessary to use series expansions of the hyperbolic functions. After expanding the hyperbolic functions and utilizing inverse-transform tables, we obtain 


$$
\begin{aligned}
& g,\left(x, x^{\prime} ; t\right)=\frac{1}{2 \sqrt{\pi D_{1} t}} \exp \left[\frac{-\left(x-x^{\prime}\right)^{2}}{4 D_{1} t}\right]-\exp \left[\frac{-\left(x+x^{\prime}\right)^{2}}{4 D_{1} t}\right] \\
& +\frac{D_{1}-\sqrt{D_{1} D_{2}}}{2 D_{1}\left(D_{1}+\sqrt{D_{1} D_{2}}\right)}\left(\sum_{r=1}^{\infty}\left(\frac{D_{1}}{\pi t}\right)^{1 / 2} \sigma^{n-1} \exp \left[-\left(\frac{2 n x_{1}-x^{\prime}-x}{4 D_{1} t}\right)^{2}\right]\right. \\
& +\sum_{n=1}^{\infty}\left(\frac{D_{1}}{\pi t}\right)^{1 / 2} \sigma^{n-1} \exp \left[-\left(\frac{2 \mathrm{nx}_{1}+\mathrm{x}^{\prime}+\mathrm{x}}{4 \mathrm{D}_{1} \mathrm{t}}\right)^{2}\right] \\
& \begin{array}{ll}
-\sum_{n=1}^{\infty}\left(\frac{D_{1}}{\pi t}\right)^{1 / 2} & \sigma^{n-1} \exp \left[-\left(\frac{2 \mathrm{nx}_{1}-x^{\prime}+x}{4 D_{1} t}\right)^{2}\right] \\
-\sum_{n=1}^{\infty}\left(\frac{D_{1}}{\pi t}\right)^{1 / 2} & \sigma^{n-1} \exp \left[-\left(\frac{2 n_{1}+x^{\prime}-x}{4 D_{1} t}\right)^{2}\right]
\end{array} \\
& g_{2}\left(x, x^{\prime} ;\right)=\frac{1}{D_{1}+k D_{2}}\left\{\sum_{n=1}^{\infty}\left(\frac{D_{1}}{\pi t}\right)^{1 / 2} \sigma^{n-1} \exp \left[-\left(\frac{2 n_{1}-x^{\prime}+k\left(x-x_{1}\right)}{4 D_{1} t}\right)^{2}\right]\right.
\end{aligned}
$$$$
-\sum_{n=1}^{\infty}\left(\frac{D_{1}}{\pi t}\right)^{1 / 2} \sigma^{n-1} \exp \left[-\left(\frac{2 n x_{1}+x^{\prime}+k\left(x-x_{1}\right)^{2}}{4 D_{1} t}\right)^{2}\right]
$$$$
\begin{aligned}
& \sigma=\frac{\sqrt{\mathrm{D}_{1} \mathrm{D}_{2}-\mathrm{D}_{1}}}{\sqrt{\mathrm{D}_{1} \mathrm{D}_{2}+\mathrm{D}_{2}}} \\
& \mathrm{k}=\left(\frac{\mathrm{D}_{1}}{\mathrm{D}_{2}}\right)^{1 / 2}
\end{aligned}
$$

- Release Fraction -

The release fraction is, of course, the quantity of real interest, since it can be compared with experiment. It is given by 


$$
\begin{aligned}
& F(t)=1-\frac{C^{i n t}(t)}{\int_{0}^{\infty} C_{0}(x) d x} \\
& C^{i n t}(t)=\int_{0}^{\infty} C(x, t) d x
\end{aligned}
$$

$c^{\text {int }}$ is given by

$$
\begin{aligned}
c^{\text {int }}(t)= & \int_{0}^{x_{1}} C_{1}(x, t) d x+\int_{x_{1}}^{\infty} C_{2}(x, t) d x \\
= & \int_{0}^{x_{1}} d x\left\{\int_{0}^{\infty} C_{0}\left(x^{\prime}\right) g_{1}\left(x, x^{\prime} ; t\right) d x^{\prime}\right\} \\
& +\int_{x_{1}}^{\infty}\left\{\int_{0}^{\infty} C_{0}\left(x^{\prime}\right) g_{2}\left(x^{\prime} x^{\prime} ; t\right) d x^{\prime}\right\} \\
= & \int_{0}^{\infty} C_{0}\left(x^{\prime}\right)\left\{\int_{0}^{x_{1}} g_{1}\left(x, x^{\prime} ; t\right) d x^{\prime}+\int_{x_{1}}^{\infty} g_{2}\left(x, x^{\prime} ; t\right) d x^{\prime}\right\}
\end{aligned}
$$

We can integrate over the Green's functions and obtain $C^{\text {int }}$ in terms of $C_{0}(x)$. After some tedious manipulation,

$$
\begin{aligned}
C^{i n t} & =\frac{1}{2} \int_{0}^{\infty} d x^{\prime} C_{0}\left(x^{\prime}\right)\left[\operatorname{erf}\left(\frac{x_{1}-x^{\prime}}{2 \sqrt{D_{1} t}}\right)-\operatorname{erf}\left(\frac{x_{1}+x^{\prime}}{2 \sqrt{D_{1} t}}\right)\right. \\
& -\frac{1}{2} \sigma \int_{0}^{\infty} d x^{\prime} C_{0}\left(x^{\prime}\right) S\left(x^{\prime}, t\right) \\
& +\frac{\sqrt{D_{1} D_{2}}}{D_{1}+D_{2}} \sum_{n=1}^{\infty} \sigma^{n-1}\left[I_{1 n}-I_{2 n}\right]
\end{aligned}
$$


where

$$
\begin{aligned}
& S\left(x^{\prime}, t\right)=\sum_{n=1}^{\infty} c^{n-1}\left\{\operatorname{erf}\left[\frac{(2 n+1)\left(x_{1}+x^{\prime}\right)}{2 \sqrt{D_{1} t}}\right]\right. \\
& +\operatorname{erf}\left[\frac{(2 \mathrm{n}-1) \mathrm{x}_{1}+\mathrm{x}^{\prime}}{2 \sqrt{\mathrm{D}_{1} t}}\right]-\operatorname{erf}\left[\frac{(2 \mathrm{n}+1) \mathrm{x}_{1}-\mathrm{x}^{\prime}}{2 \sqrt{\mathrm{D}_{1} t}}\right] \\
& \left.-\operatorname{erf}\left[\frac{(2 n-1) x_{1}-x^{\prime}}{2 \sqrt{D_{1} t}}\right]\right\} \\
& I_{\ln }=\int_{0}^{\infty} C_{0}\left(x^{\prime}\right) \operatorname{erfc}\left(\frac{2 n x_{1}-x^{\prime}}{2 \sqrt{D_{1} t}}\right) d x^{\prime} \\
& I_{2 n}=\int_{0}^{\infty} C_{0}\left(x^{\prime}\right) \operatorname{erfc}\left(\frac{2 n x_{1}+x^{\prime}}{2 \sqrt{D_{1} t}}\right) d x^{\prime} \\
& \sigma=\frac{\sqrt{D_{1} D_{2}}-D_{1}}{\sqrt{D_{1} D_{2}}+D_{1}}
\end{aligned}
$$




\section{$\underline{\text { DISTRIBUTION }}$}

No. of

Copies

OFFSITE

1 ERDA Chicago Patent Group 9800 South Cass Avenue Argonne, IL 60439

A. A. Churm

27 ERDA Technical Information Center

10 Joint Center for Graduate Study

100 Sprout Road

Richland, WA 99352

L. C. 01 sen
No. of

Copies

ONSITE

1 ERDA Richland Operations

Office

$\overline{\text { Programs Division }}$

D. K. Jones

15 Battel le-Northwest

T. D. Chikalla

C. A. Oster (1)

R. P. Turcotte (10)

Technical Information Files 